\title{
LA LIMITACIÓN A LA DEDUCIBILIDAD DE LOS GASTOS FINANCIEROS EN EL IMPUESTO SOBRE SOCIEDADES: EVOLUCIÓN Y ANÁLISIS COMPARATIVO
}

\author{
The limitation on interest deductions in the Law of Spain \\ and the Basque Country: Evolution and Comparison
}

\author{
Irene Martinez Martinez \\ Universidad de Deusto \\ irenemartinez.imm@gmail.com \\ http://dx.doi.org/10.18543/ed-67(2)-2019pp355-394 \\ Recibido: 21.10.2019 \\ Aceptado: 18.11.2019
}

\section{Resumen}

El presente trabajo tiene por objeto dar una visión de la evolución en el tratamiento legal de la limitación a la deducibilidad de los gastos financieros como medio para evitar la elusión fiscal, tanto a nivel supranacional, como nacional y, más concretamente, foral, así como analizar las cuestiones más problemáticas que surgen de la aplicación de esta limitación. En la actualidad, es patente la preocupación de los países de la OCDE y de otros organismos supranacionales por el fraude fiscal y la elusión de impuestos, fenómenos que se han generado como productos derivados de la globalización y que utilizan los gastos financieros como una de sus herramientas más habituales por la facilidad con la que permite el traslado de bases imponibles a territorios de menor o nula tributación.

\section{Palabras clave}

Gastos financieros, BEPS, elusión, subcapitalización, Impuesto sobre Sociedades. 


\section{Abstract}

This essay intends to give a broad vision on the legal treatment of the limitation on interest deductions understood as a tool for tax avoidance at a supranational, Spanish internal law and, more specifically, special-foral basque law, and to analyse the most problematic issues this limitation raises. Nowadays, the concern that the OCDE and other supranational organisations have on tax fraud and evasion is manifest. This phenomenon has developed as a by-product of globalization and uses interest deductions as one of the most usual tools for base erosion and profit shifting.

\section{Keywords}

Limitation on Interest Deductions, evasion, BEPS, action 4, Corporate Tax. 


\begin{abstract}
SUMARIO: I. INTRODUCCIÓN: CONTEXTO DE LAS NORMAS SOBRE SUBCApitalización. II. Medidas de Derecho Internacional Público y Derecho Comunitario. 1. Plan BEPS. 2. Anti Tax Avoidance Package. III. LAS NORMAS ANTI-SUBCAPITALIZACIÓN Y SUS PROBLEMAS DE INCOMPATIBILIDAD. 1. El principio de independencia y la subcapitalización en el Modelo Convenio de la OCDE. 2. La norma anti-subcapitalización en el ordenamiento jurídico español. IV. De LA SUBCAPITALIZACIÓN A LA LIMITACIÓN A LA DEDUCIBILIDAD DE GASTOS FINANCIEROS EN EL ORDENAMIENTO JURÍDICO ESPAÑOL. V. EL TRATAMIENTO DE LOS GASTOS FINANCIEROS EN LA LEY 27/2014, DEL IMPUESTO SOBRE SociedAdes. 1. El límite general del artículo 16 de la Ley 27/2014, del Impuesto sobre Sociedades. 2. La limitación a la deducibilidad de gastos financieros en la compra de acciones apalancada. 3. La no deducibilidad de gastos financieros en las operaciones intragrupo. VI. EL TRATAMIENTO DEL EXCESO DE GASTOS FINANCIEROS EN LA Norma Foral del Impuesto Sobre Sociedades De BizKaia. 1. El origen de la regla de subcapitalización en la Norma Foral del Impuesto sobre Sociedades de Bizkaia. 2. La regla de subcapitalización de la Norma Foral 11/2013, del Impuesto sobre Sociedades. 3. Efectos del artículo 47 de la Norma Foral del Impuesto sobre Sociedades. 4. La limitación a la deducibilidad de gastos financieros en la Norma Foral 11/2013. 5. El doble límite del artículo 47 de la Norma Foral del Impuesto sobre Sociedades y su conciliación con el artículo 25.bis. VII. CONCLUSIÓN. BIBLIOGRAFIA Y FUENTES.
\end{abstract}

\title{
I. INTRODUCCIÓN: CONTEXTO DE LAS NORMAS SOBRE SUBCAPITALIZACIÓN
}

Desde la óptica tributaria, a la financiación con recursos ajenos se le otorga un tratamiento divergente frente a la financiación con fondo propios, lo cual resulta en una carga tributaria final diferente tanto para el sujeto que percibe la financiación como para aquel que la aporta, como consecuencia del diferente régimen tributario aplicable a la remuneración de uno y otro tipos de financiación ${ }^{1}$.

Mientras que en el primer caso dicha retribución la constituye el pago de intereses, que, en general, tienen carácter de gasto deducible en el Impuesto sobre Sociedades, la financiación con recursos propios se remunera con dividendos, que no gozan de dicho carácter. Desde la perspectiva del financiador los intereses son una renta sujeta a gravamen mientras que los dividendos,

${ }^{1}$ C. Taboada, «La subcapitalización y los convenios de doble imposición». En Revista de Contabilidad y Tributación, núm. 137/138, (1995), 79. 
sujeto al cumplimiento de determinados requisitos, se consideran exentos para el accionista persona jurídica.

Esta diferencia de tratamiento entre financiación ajena y propia incide directamente sobre la base imponible de los sujetos, lo cual se agudiza cuando nos referimos a estructuras de financiación transfronterizas ${ }^{2}$, en las que entran en juego las diferencias impositivas entre países, que hacen que la operación pueda no tener un carácter netamente neutro tomando en consideración el grupo de entidades afectadas. En atención a lo anterior, por tanto, la decisión sobre cómo financiar una sociedad tiene importantes consecuencias fiscales, no existiendo, en principio, ninguna limitación respecto a dicha decisión ${ }^{3}$. Ello implica que en el contexto de un grupo de sociedades pudiera resultar ventajoso que la matriz financie a una de las filiales mediante préstamos, en lugar de mediante aportación de capital para obtener un trato fiscal más favorable ${ }^{4}$.

Como reconoce la Organización para la Cooperación y el Desarrollo Económicos (en adelante, $\mathrm{OCDE}^{5}$ ), el dinero es un bien móvil y fungible, y dicho carácter, junto con la globalización y apertura comercial, facilitan el flujo de capitales financieros. Ello permite a los grupos multinacionales financiar sus operaciones transfronterizas de forma óptima y eficiente mediante recursos tanto propios como ajenos ${ }^{6}$, dando lugar a la obtención de mejores resultados al incidir sobre su nivel de endeudamiento, minimizando sus obligaciones tributarias.

Los grupos multinacionales pueden obtener dicho resultado bien mediante el ajuste de la deuda del grupo, bien con la utilización de instrumentos financieros para realizar pagos equivalentes a los intereses pero no sometidos a la limitación de la deducibilidad de estos ${ }^{7}$. Al concentrar los grupos la financiación ajena en algunas de las entidades del grupo, consiguen disminuir la base

${ }^{2}$ R. Fuster Tozer, C. Durán Haeussler, J. Villalón Pérez-Artacho, A.L. Artamendi Gutiérrez, «Capítulo IV. Acción 4: Limitación de la erosión de la base imponible por vía de deducciones de intereses y otros gastos financieros» en Plan de acción BEPS: Una reflexión obligada. (Madrid: Fundación de Impuestos y Competitividad, 2017), 97-98.

${ }_{3}^{3}$ F.A.Veha Borrego, «La norma tributaria en materia de subcapitalización: incidencia de los convenios de doble imposición y del derecho comunitario» en Crónica Tributaria $n^{\circ} 104$, (2002), 5-6.

${ }^{4}$ Conclusiones del Abogado General Sr. L.A. Geelhoed presentadas el 29 de junio de 2006- Asunto C-524/04.

5 OCDE, «Resúmenes. Informes Finales 2015» en Proyecto OCDE/G20 sobre la Erosión de la Base Imponible y el Traslado de Beneficios (2015), p. 17.

${ }^{6}$ R. Fuster Tozer, C. Durán Haeussler, J..., op. cit., 97.

7 B. Parejo García, «La regla de la delimitación de deducibilidad de intereses» en $L a$ armonización de las normas contra la elusión fiscal relativas a la fiscalidad directa en la Unión Europea por J.M. Almuní Cid (Cizur Menor: Ed. Aranzadi S.A.U. 2018), 1. 
imponible del mismo y localizarla en otros territorios, alejándose del principio por el que se habría de tributar en un determinado territorio por los beneficios que en él se generan ${ }^{8}$.

En la actualidad, es considerable la preocupación de los países de la OCDE y de otros organismos internacionales por el fraude fiscal y la elusión de impuestos, que se ha generado como producto derivado del fenómeno de la globalización. Así, se observa el incremento en la constitución de empresas en territorios poco o nada colaboradores con las autoridades tributarias de otros países y con sistemas de baja o nula tributación, trasladando a ellos los beneficios obtenidos, como parte de lo que se ha venido a denominar política fiscal agresiva ${ }^{9}$. A pesar de los esfuerzos a nivel internacional y supranacional para promover la armonización de los sistemas impositivos nacionales, no se ha conseguido desarrollar una normativa fiscal internacional coordinada, dejando la puerta abierta, en consecuencia, a la utilización de estructuras fiscales que permiten minorar la tributación ${ }^{10}$, incrementando en consecuencia la competencia fiscal entre Estados ${ }^{11}$.

El presente trabajo tiene por objeto dar una visión de la evolución en el tratamiento legal de la limitación a la deducibilidad de gastos financieros como medio para evitar la elusión fiscal, tanto a nivel supranacional, como nacional y, más concretamente, foral, así como analizar las cuestiones más problemáticas que surgen de la aplicación de esta limitación.

\section{MEDIDAS DE DERECHO INTERNACIONAL PÚBLICO Y DERECHO COMUNITARIO}

\section{Plan BEPS}

Con las siglas BEPS (Base Erosion Profit Shifting) se alude a las estrategias de planificación fiscal que explotan los vacíos y desajustes legales para desplazar beneficios a territorios de baja o ninguna imposición a través de esquemas que, en la mayoría de los casos, no son ilegales pero atentan contra la justicia e integridad de los sistemas fiscales al permitir a las empresas que operan a nivel internacional conseguir ventajas competitivas sobre las

${ }^{8}$ I. Alonso Arce, La limitación a la deducción de gastos financieros en el Impuesto sobre Sociedades. Forum Fiscal no 234. Junio 2018.

9 J.M., Lago Montero, «Planificación fiscal agresiva, BEPS y litigiosidad», Ars Iuris Salmanticensis. Estudios. Vol. 3, (2015), 55-73.

${ }^{10}$ R. Fuster Tozer, C. Durán Haeussler, J..., op. cit., 97.

${ }_{11}$ M.A. Gómez Suárez, La intervención de la fiscalidad en el desplazamiento interjurisdiccional de las estructuras financieras de los grupos multinacionales (A Coruña: Universidade Da Coruña, 2015), 2. 
empresas que operan a nivel doméstico ${ }^{12}$. Así, en 2013, la OCDE y los países miembros del G20 adoptaron un plan compuesto de quince acciones contra la erosión de la base imponible y el traslado de beneficios que han de ser implementadas a través de reformas de la legislación doméstica y de los tratados internacionales ${ }^{13}$. Este proyecto tiene por finalidad evitar la planificación fiscal agresiva, asegurar que los beneficios son gravados en el territorio en el que se generan, posibilitar un intercambio automático de información entre las administraciones tributarias y frenar la erosión de la base imponible y el traslado de beneficios ${ }^{14}$. Las acciones, que se configuran como recomendaciones y propuestas y no como normas jurídicamente vinculantes, se articulan en torno a tres ejes: nuevos estándares internacionales para asegurar la coherencia del impuesto sobre sociedades a nivel internacional, realinear la fiscalidad sobre la base de la sustancia de las actividades económicas y mejora de la transparencia ${ }^{15}$, y son desarrolladas por una serie de informes cuya versión definitiva fue publicada en octubre de 2015. Dichos informes configuran unos estándares mínimos, metodologías comunes y recomendaciones de nuevas prácticas $^{16}$, así como otras medidas tendentes a revisar los estándares internacionales para la eliminación de la doble imposición, entre las cuales se encuentra la limitación a la deducibilidad de los gastos financieros 9 .

El Informe BEPS identificó que, de hecho, «el uso de los gastos financieros por los grupos multinacionales es uno de los mecanismos de planificación fiscal internacional más sencillos para desplazar bases imponibles.» ${ }^{17}$ Los grupos, de acuerdo a los Informes Finales BEPS ${ }^{18}$, hacen uso de instrumentos financieros para realizar pagos de intereses mediante formas jurídicas diversas para sortear la limitación de la deducibilidad de gastos financieros,

12 OCDE. «Progress report July 2017-June 2018» en OECD/G20 Inclusive Framework on BEPS. 2018, p. 4.

13 OECD, Limiting Base Erosion Involving Interest Deductions and Other Financial Payments, Action 4, 2015 Final Report, OECD/G20 Base Erosion and Profit Shifting Project. Paris: OECD Publishing. 2015. http://dx.doi.org/10.1787/9789264241176-en (Última consulta 21 de marzo de 2019).

${ }_{14}$ I. Otaegi, D. Armesto, «Fiscalidad Internacional» del máster en Asesoría Fiscal. Cámara de Comercio, Bilbao.

${ }^{15}$ F. Martínez Sesma, Medidas del proyecto BEPS implantadas por la UE y en el reino de España: territorio de régimen común y territorios forales (I). Forum Fiscal $\mathrm{n}^{\mathrm{o}}$ 244, julio 2018.

${ }_{16}$ D.T. Mendoza López, F. Valdez Aguirre, El plan de acción OCDE/G20 en la construcción del pacto global por la justicia fiscal (Cizur Menor: Editorial Aranzadi, S.A.U. 2018), 3 .

17 S. López Ribas, El principio de libre competencia y los gastos financieros (LA LEY 788/2016, 2016), 5.

${ }^{18}$ OCDE, «Resúmenes. Informes Finales 2015» en Proyecto OCDE/G20 sobre la Erosión de la Base Imponible y el Traslado de Beneficios. 2015, p. 17. 
erosionando de dicha manera su base imponible a través del traslado de beneficios. Así, el grupo «concentra un elevado nivel de deuda en entidades independientes de países con alta tributación», o «utiliza préstamos intragrupo para generar deducciones por intereses superiores a los gastos efectivamente incurridos por pago de intereses a terceros»o «utiliza financiación obtenida de empresas del grupo o a entidades independientes para generar rentas no sometidas a gravamen».

En concreto, la Acción 4 del Informe de la OCDE, siguiendo la línea marcada por la Resolución del ECOFIN de 8 de junio de 2010, pretende «limitar la erosión de la base imponible por vía de deducciones en el interés y otros pagos financieros ${ }^{19} \gg$. Considera que la deducción excesiva de intereses debe ser abordada de manera coordinada entre los países por los riesgos que implica para la competencia y para evitar que se genere una doble imposición. Así, la OCDE propone una metodología común para prevenir ese fenómeno e insta al diseño de normas para prevenir la erosión de bases imponibles y el traslado de beneficios mediante la deducción de intereses. En concreto, sugiere dos normas: un ratio fijo y un ratio global. Recomienda la fijación de un ratio que limite las deducciones netas por intereses de la entidad a un porcentaje de entre el $10 \%$ y el $30 \%$ del beneficio antes de intereses, depreciaciones y amortizaciones e impuestos o EBITDA, y que será, como mínimo, aplicable, a entidades que formen parte de un grupo. Dicho límite puede ser complementado por un ratio global a nivel de grupo que permita superar el primero en circunstancias determinadas. De esta manera se pretende que los gastos financieros realmente deducidos guarden relación directa con la renta imponible derivada de la actividad económica de la entidad y evita, en efecto, la doble imposición.

Al amparo de la acción 4, se permite la adopción de otras disposiciones como la fijación de un umbral impositivo deducible mínimo, la exclusión de intereses pagados a terceros prestamistas, la no sujeción del sector bancario y de seguros a estas normas o la traslación o imputación de gastos por intereses no deducidos y la capacidad no utilizada a ejercicios subsiguientes.

Los informes finales de BEPS son instrumentos de soft law, por lo que requieren de la labor de los gobiernos para su implementación a través de legislación.

\section{Anti Tax Avoidance Package}

El Anti Tax Avoidance Package (en adelante ATAP), que refleja una clara apuesta de la Unión Europea por la armonización de las soluciones

19 OCDE, «Nota explicativa. Informes Finales 2015» en Proyecto OCDE/G20 sobre la Erosión de la Base Imponible y el Traslado de Beneficios. 2015, p. 17. 
adoptadas en materia de elusión fiscal ${ }^{20}$, forma parte de la agenda de la Comisión Europea en aras de una imposición corporativa más justa, simple y efectiva en la Unión Europea que garantice una fiscalidad eficaz, transparencia fiscal y condiciones equitativas ${ }^{21}$ a través de medidas de prevención de la planificación fiscal agresiva y de transparencia, llamando a los Estados Miembros a llevar a cabo una acción coordinada contra la evasión fiscal ${ }^{22}$. Dentro de los elementos que componen este «paquete» se encuentra la Directiva (UE) 2016/1164 del Consejo, de 12 de julio ${ }^{23}$, o Directiva anti-abuso por la que se establecen normas contra las prácticas de elusión fiscal que inciden directamente en el funcionamiento del mercado interior, también conocida como Anti Tax Avoidance Directive o ATAD, principal exponente de la denominada «BEPS europea» ${ }^{24}$. ATAD, que fue reformada en 2017 por la Directiva (UE) 2017/952 del Consejo, de 29 de mayo de 201725,26 (ATAD II), contiene cinco medidas anti-abuso con carácter vinculante que deben ser aplicadas por los Estados para combatir las formas habituales de la planificación fiscal agresiva y que han de ser de aplicación desde el 1 de enero de $2019^{27}$. Entre ellas se encuentra la limitación en la deducibilidad de intereses, que tiene como finalidad desincentivar los ajustes de la deuda con el objeto de minimizar la tributación y que sigue en general lo recomendado por la acción 4 de BEPS.

El artículo 4 de esta Directiva, bajo la rúbrica «Norma relativa a la limitación de los intereses» establece una ceiling rule, que limita la deducibilidad de los intereses al 30\% del EBITDA del contribuyente, y una serie de medidas de escape que permiten la no limitación de la deducibilidad cuando los gastos no superen los tres millones de euros, no limitación para entidades

${ }^{20}$ I. Merino Jara, BEPS, Unión Europea y Hacienda Foral. Proyecto de Investigación «La residencia fiscal ante la diversidad de poderes tributarios desde la perspectiva del País Vasco» (DER2015-63533-C4-1-P. MINECO/FEDER).

${ }^{21}$ F. Martínez Sesma, op. cit.

${ }^{22}$ EUROPEAN COMMISSION. Anti Tax Avoidance Package. https://ec.europa.eu/ taxation_customs/business/company-tax/anti-tax-avoidance-package_en (Última consulta 9 de marzo de 2019).

${ }^{23}$ Directiva (UE) 2016/1164 del Consejo, de 12 de julio. «DOUE» L 193/1, de 19 de julio de 2016 .

${ }^{24}$ C. García, La deducibilidad de gastos financieros en el Impuesto de Sociedades (Madrid: Marcial Pons, 2016) 13.

${ }_{25}$ Directiva (UE) 2017/952 del Consejo, de 29 de mayo de 2017. «DOUE» L 144/1, de 7 de junio de 2017.

${ }^{26}$ La Directiva 2017/952 introdujo dos nuevos incisos, el inciso ii de la letra a del apartado 5 y el apartado 8, al artículo 4 de la Directiva 2016/1164.

${ }^{27}$ EUROPEAN COMMISSION. The Anti Tax Avoidance Directive. https://ec.europa.eu/taxation_customs/business/company-tax/anti-tax-avoidance-package/anti-taxavoidance-directive_en (Última consulta 9 de marzo de 2019). 
aisladas, no pertenecientes a un grupo, y una ratio global de grupo que habilita la deducibilidad de intereses por encima del ratio fijo en atención al gasto financiero neto y EBITDA del grupo a nivel mundial.

La Directiva se constituye como una norma de mínimos, pudiendo los Estados incrementar las exigencias dentro del respeto de las libertades fundamentales, y se plantea como una solución temporal hasta la adopción en la Unión Europea de una Directiva relativa a una base imponible consolidada común del Impuesto sobre Sociedades (BICCIS o CCCTB) en la que trabaja el Consejo ${ }^{28}$.

\section{LAS NORMAS ANTI-SUBCAPITALIZACIÓN Y SUS PROBLEMAS DE INCOMPATIBILIDAD}

\section{El principio de independencia y la subcapitalización en el Modelo Convenio de la OCDE}

El principio de independencia o libre competencia o arm's length principle tiene por objeto garantizar la distribución del poder tributario de los Estados en relación con las rentas internacionales ${ }^{29}$ y exige que las partes en una transacción, incluso las vinculadas, deban actuar como sujetos independientes, con sujeción a las condiciones de mercado.

Ello se traduce, en lo relativo a los gastos financieros por endeudamiento de empresas vinculadas, en una serie de reglas de valoración plasmadas en el artículo 9 del Modelo Convenio OCDE ${ }^{30}$ y en las Directrices sobre Precios de Transferencia de la $\mathrm{OCDE}^{31}$, así como en la regulación de los gastos financieros derivados de un exceso de endeudamiento con entidades vinculadas no residentes en los ordenamientos jurídicos nacionales ${ }^{32}$.

Un préstamo concedido en situación de mercado se define como aquel que habrían obtenido partes no vinculadas ${ }^{33}$, de suerte que el pago de

${ }^{28}$ CONSEJO EUROPEO. CONSEJO DE LA UNIÓN EUROPEA. Base imponible consolidada común del Impuesto sobre Sociedades. https://www.consilium.europa.eu/es/ policies/ccetb/ (Última consulta 9 de marzo de 2019).

${ }^{29}$ F.A. Vega Borrego, op. cit., 7.

${ }^{30}$ OCDE. Modelo de Convenio Tributario sobre la Renta y sobre el Patrimonio. 2010, p. 188.

31 OCDE. Directrices de la OCDE aplicables en materia de precios de transferencia a empresas multinacionales y administraciones tributarias. 2010, p. 40.

32 S. López Ribas, El principio de libre competencia y los gastos financieros (LA LEY 788/2016, 2016).

${ }^{33}$ Distinguen algunos autores (LÓPEZ RIBAS) a este respecto entre lo que denominan «could approach»y «would have approach». Así, el primero entiende que el importe máximo de endeudamiento que generaría intereses deducibles es aquel que un tercero independiente habría prestado, mientras que el segundo defiende que dicho importe se 
intereses que no satisfaga dicha condición será considerado, de acuerdo al artículo 9.1 del Modelo Convenio, como participación en beneficios ${ }^{34}$.

Los propios comentarios al Modelo Convenio prevén que los Estados puedan aplicar sus propias normas de subcapitalización siempre que su efecto sea asimilar los beneficios obtenidos por el prestatario a la cantidad que habría obtenido en una situación de libre competencia, sin incrementar la base imponible de la entidad doméstica más de lo que se habría obtenido de acuerdo al principio de libre competencia.

\section{La norma anti-subcapitalización en el ordenamiento jurídico español}

En el ordenamiento jurídico español se abordó la problemática relativa a los gastos financieros por endeudamiento de empresas vinculadas mediante una regla de subcapitalización. La subcapitalización se conceptúa como aquella situación en la que, por la prevalencia de los fondos ajenos sobre los propios, la entidad minora su carga tributaria, disminuyéndose de esta manera la recaudación de la Hacienda Pública ${ }^{35}$. Este fenómeno de manipulación de la proporción de endeudamiento y capital ha sido considerado abusivo por muchos Estados dando lugar a medidas para prevenir su utilización.

En la Ley del Impuesto sobre Sociedades de $1978^{36}$, en su artículo 16.9, fruto de la modificación operada por la Ley 18/1991, del Impuesto sobre la Renta de las Personas Físicas ${ }^{37}$, se contemplaban los efectos tributarios derivados de los préstamos realizados por entidades vinculadas no residentes en condiciones distintas a las de mercado con el ánimo de obtener una minoración de la carga fiscal por medio de la deducción de intereses, estableciéndose reglamentariamente un coeficiente máximo de endeudamiento sobre capital ${ }^{38}$.

determina en referencia al importe de endeudamiento que el prestatario habría suscrito de haber actuado en condiciones de libre competencia por responder a la necesidad comercial del prestatario.

${ }^{34}$ OCDE. Model Tax Convention on Income and on Capital (Condensed version as it to read on 21 november 2017). 2017, p. 226.

35 E. Cencerrado Millán, «La subcapitalización» en Fiscalidad de los precios de transferencia (operaciones vinculadas), 637.

${ }^{36}$ Ley 61/1978, de 27 de diciembre, del Impuesto sobre Sociedades («BOE» núm. 312 , de 30 de diciembre de 1978).

${ }^{37}$ Ley 18/1991, de 6 de junio, del Impuesto sobre la Renta de las Personas Físicas («BOE» núm. 136, de 7 de junio de 1991).

38 Z. Chevarría, «La naturaleza jurídica de la norma de subcapitalización y su aplicación práctica como norma doméstica antielusión en el Reino de España», Revista del Departamento Académico de Ciencias Administrativas, año 3, número 5. (2008), 14. 
Es en la Ley del Impuesto de Sociedades de $1995^{39}$ donde, en su artículo 20, se establece por primera vez una norma de subcapitalización propiamente dicha. Dicho precepto preveía un ratio fijo sobre la cifra del capital fiscal medio del periodo impositivo de suerte que los intereses correspondientes al endeudamiento neto medio del periodo impositivo que superase el importe de tres veces dicha cifra tendrían la consideración de dividendos. A los efectos de la aplicación de este artículo solo era tenido en cuenta el endeudamiento neto de una entidad «con otra $u$ otras personas o entidades no residentes en territorio español con las que esté vinculada» y excluía de su ámbito de aplicación a las entidades financieras. Permitía el apartado tercero del precepto, toda vez que existiera un convenio de doble imposición entre los Estados de las entidades prestamista y prestataria, la sumisión de una propuesta de coeficiente distinto a la Administración tributaria «fundada en el endeudamiento que el sujeto pasivo hubiera podido obtener en condiciones normales de mercado con personas o entidades no vinculadas», de acuerdo con lo dispuesto por las normas de precios de transferencia contenidas por el artículo 16.6 del mismo cuerpo legal.

El Tribunal de Justicia de la Unión Europea ha mostrado su disconformidad con las normas anti-abuso que se aplican sin que se verifique la concurrencia de fraude, exigiendo, en cualquier caso, el respeto de las libertades fundamentales ${ }^{40}$.

En este sentido, en la sentencia Lankhorst-Hohorts del TJUE ${ }^{41}$ recaída en el asunto C-324/00, se declara que la normativa alemana de subcapitalización contenida en la ley del impuesto de sociedades alemán, similar a la entonces vigente en España y en los territorios forales, era contraria a la libertad de establecimiento promulgada por el artículo 49 del Tratado de Funcionamiento de la Unión Europea (antiguo artículo $43 \mathrm{TCE})^{42}$. Consideró el TJUE que la normativa alemana no se limitaba a sancionar montajes puramente artificiales tendentes a minorar la carga tributaria sino que se aplicaba a cualquier situación en la que la sociedad matriz estuviera domiciliada fuera de Alemania.

Entiende dicho Tribunal, además, que concurre vulneración de la libertad de establecimiento cuando se introduce una diferencia de trato entre filiales

${ }^{39}$ Ley 43/1995, de 27 de diciembre, del Impuesto sobre Sociedades («BOE» núm. 310 , de 28 de diciembre de 1995).

40 V. Ruiz Almendral, «Subcapitalización y libertad de establecimiento: el caso «Test Claimants in the Thin Cap Group Litigation» como una oportunidad para rehabilitar el artículo 20 del TRLIS» (2008), 26, citado en J.A. Barciela Pérez, «Subcapitalización y libre circulación de capitales. El asunto Itelcar C-282/12» (BIB 2014\2156).

${ }^{41}$ Sentencia del Tribunal de Justicia de la Unión Europea (Sala Quinta) de 12 de diciembre de 2002, as. C-324/00, Lanhorst Hohorst (ECLI:EU:C:2002:749).

42 Tratado de Funcionamiento de la Unión Europea, «DOUE» C 326/49. 
residentes según si su matriz está o no domiciliada en el país en cuestión (en este caso, Alemania), por hacer menos atractivo el ejercicio de la libertad de establecimiento por sociedades domiciliadas en un Estado Miembro distinto de aquel en el que se adoptare dicha disposición, y siempre que dicha diferencia no estuviera justificada por «razones imperiosas de interés general».

Para la adaptación de la normativa española a la jurisprudencia comunitaria, la Ley $62 / 2003^{43}$, añadió un apartado cuarto al artículo 20 de la Ley de Impuesto de Sociedades de 1995, por el cual la norma anti-subcapitalización «no será de aplicación cuando la entidad vinculada no residente en territorio español sea residente en otro Estado miembro de la Unión Europea, salvo que resida en un territorio calificado reglamentariamente como paraíso fiscal», ampliando el Tribunal Supremo la exclusión a países con los que España tuviera suscrito un convenio de doble imposición ${ }^{44}$.

Así, por tanto, la aplicación de la norma anti-subcapitalización del artículo 20 de la LIS, tras la reforma operada por la Ley 62/2003, exigía la concurrencia de una serie de requisitos:

- Vinculación entre la persona o entidad prestamista y prestataria.

- Que la sociedad residente estuviera endeudada con personas o entidades no residentes en la Unión Europea o localizadas en un territorio calificado como paraíso fiscal.

- Que el endeudamiento neto remunerado medio del periodo impositivo excediera del triple del capital fiscal medio de dicho periodo.

La modificación operada en el artículo 20 fue criticada por la doctrina por considerarla desproporcionada ${ }^{45}$, puesto que se excluía de su aplicación a todas las entidades vinculadas de la Unión Europea, salvo que estuvieran en un paraíso fiscal, sin tomar en consideración si se trataba o no de un montaje puramente artificial. Esta postura se vió apoyada por sentencias posteriores del TJUE como Test claimants in the Thin Group Litigation ${ }^{4647}$ y Lammers \&

${ }^{43}$ Ley 62/2003, de 30 de diciembre, de medidas fiscales, administrativas y del orden social («BOE» núm. 313, de 31 de diciembre de 2003).

${ }_{44}$ Sentencia del Tribunal Supremo (Sala 3 ${ }^{\mathrm{a}}$ ) de 1 de octubre de 2009, no 1696/2004 (RJ 2010\947).

45 J.M. Calderón Carrero, «STJCE 13.3.2.007, C-524/04, Asunto Test Claimants in the Thin Cap Group: las Condiciones de compatibilidad comunitaria de las cláusulas de subcapitalización (y de precios de transferencia)» en Crónica Tributaria $n^{\circ} 155$ (2015), 15. citado en J.A. Barciela Pérez, op. cit.

46 Sentencia del Tribunal de Justicia de la Unión Europea (Gran Sala) de 13 de marzo de 2007, as. C-524/04, Test Claimants in the Thin Cap Group Litigation. (ECLI:EU:C:2007:161).

${ }^{47}$ Este pronunciamiento se muestra a favor de la legalidad de las normas nacionales anti-subcapitalización que imponen restricciones basadas en un test de actuación como partes independientes, posibilitando que la filial pruebe que la operación se realizó por 
Van Cleeff8. En efecto, estos pronunciamientos afirman la compatibilidad de las normas anti-subcapitalización con la normativa comunitaria siempre y cuando se refieran a préstamos que no responden a las condiciones de mercado y la no deducibilidad de los intereses se halle limitada al exceso de estos sobre los que hubieran pactado entidades independientes en condiciones de mercado ${ }^{49}$, debiendo limitarse su aplicación a «montajes puramente artificiales» ${ }^{50}$. Ello abría la posibilidad de aplicación de dichas normas a otros residentes de la Unión Europea en el caso de que se tratara de montajes puramente artificiales, sin sustancia económica, y se consolidó la consideración de que aquellas normas anti-subcapitalización aplicables al endeudamiento con entidades vinculadas no residentes sin posibilidad de prueba de adecuación a las condiciones de mercado (como en el caso de Lankhorst-Hohorst), serían contrarias al ordenamiento comunitario.

La Resolución del Consejo ECOFIN de 8 de junio de 2010 sobre la coordinación de las normas de subcapitalización en la Unión Europea, estableció una serie de recomendaciones en esta materia y reiteró el potencial de estas normas para evitar la elusión fiscal siempre y cuando respetaran el principio de independencia.

Cuando parecían haberse superado las incompatibilidades con el principio de independencia, una serie de pronunciamientos del Tribunal Supremo determinaron que una norma anti-subcapitalización en la que se discrimina a la prestamista en función de su residencia fiscal era contraria al principio de no discriminación ${ }^{51}$. El principio de no discriminación, plasmado en numerosos Convenios para evitar la Doble Imposición, se encuentra enunciado en el artículo 24 del Modelo Convenio de la OCDE que, en su apartado cuarto, establece que «los intereses (...) pagados por una empresa de un Estado contratante

motivos comerciales distintos de la obtención de una ventaja fiscal y siempre y cuando el país en cuestión (Reino Unido) garantice el reconocimiento recíproco por el Estado de residencia de la matriz de cualquier recalificación de los intereses pagados por la filial hecha por el Reino Unido.

48 Sentencia del Tribunal de Justicia (Sala Cuarta) de 17 de enero de 2008, as. C-105/07, Lammers \& Van Cleeff.

49 R. Falcón y Tella, «La subcapitalización, las ETVE y la planificación fiscal «de riesgo» (Res. TEAC 25 junio 2009)» en Revista Quincena Fiscal núm. 22/2009 parte Editorial (Cizur Menor: Editorial Aranzadi, S.A.U., 2009) 4.

${ }^{50}$ Comunicación de 10 de diciembre de 2007 de la Comisión al Consejo, al Parlamento Europeo y al Comité Económico y Social Europeo sobre aplicación de medidas contra las prácticas abusivas en el ámbito de la fiscalidad directa dentro de la UE y en relación con terceros países.

${ }_{51}$ Sentencia del Tribunal Supremo (Sala $3^{\mathrm{a}}$ ) de 17 de marzo, $\mathrm{n}^{\mathrm{o}} 1825 / 2011\left(\mathrm{n}^{\mathrm{o}}\right.$ rec. 5871/2006); Sentencia del Tribunal Supremo (Sala $3^{\mathrm{a}}$ ) de 1 de octubre, $\mathrm{n}^{\mathrm{o}} 7460 / 2009\left(\mathrm{n}^{\mathrm{o}}\right.$ rec. $1596 / 2004)$. 
a un residente del otro Estado contratante serán deducibles para determinar los beneficios sujetos a imposición de dicha empresa, en las mismas condiciones que si se hubieran pagado a un residente del Estado mencionado en primer lugar». En atención a esto, lo dispuesto en el artículo 20 de la Ley del Impuesto sobre Sociedades de 1995, solo aplicable a no residentes en la Unión Europea o en paraísos fiscales, parecía contravenir lo previsto por el Modelo Convenio. Prevé, sin embargo, este último, la compatibilidad de las normas anti-subcapitalización internas siempre que estas sean, a su vez, compatibles con sus artículos 9.1 y 11.6, relativas al principio de competencia o arm's length principle, Por tanto, a pesar de su aplicabilidad exclusiva a prestamistas no residentes, su adecuación a las exigencias del principio de independencia hacen la norma de subcapitalización compatible con el principio de no discriminación.

No obstante, el Tribunal de Justicia de la Unión Europea en el caso Itel$\operatorname{car}^{52}$ puso de manifiesto la existencia de más incompatibilidades de la norma anti-subcapitalización, declarando la incompatibilidad de la norma portuguesa con la libertad de circulación de capitales. En virtud de dicho pronunciamiento, no podía admitirse la aplicación de la norma no solo cuando la entidad fuera residente en la Unión Europea, sino también cuando se hubiera firmado un Convenio para evitar la Doble Imposición con cláusula de no discriminación y con cualquier Estado tercero, lo que afectaba a la normativa vigente en territorio común y foral ${ }^{53}$.

\section{DE LA SUBCAPITALIZACIÓN A LA LIMITACIÓN A LA DEDUCIBILIDAD DE GASTOS FINANCIEROS EN EL ORDENAMIENTO JURÍDICO ESPAÑOL}

La problemática de la compatibilidad de las normas anti-subcapitalización españolas con el Derecho Comunitario y los Convenios de Doble Imposición suscritos por España en relación con el principio de no discriminación y las libertades fundamentales, así como la dificultad de probar la existencia de financiación indirecta, dieron lugar, como se ha mencionado previamente, a pronunciamientos del Tribunal Supremo Español que, en consonancia con los pronunciamientos del Tribunal Superior de Justicia de la Unión Europea, declaró no haber duda de la «incompatibilidad de la norma española controvertida -el art. 16.9 de la Ley 61/1978, en la redacción dada por la Ley 18/1991con la libertad de establecimiento» y el principio de no discriminación ${ }^{54}$.

${ }^{52}$ Sentencia del Tribunal de Justicia de la Unión Europea (Sala Cuarta) de 3 de octubre de 2013, as. C-282/2012, Itelcar. (ECLI:EU:C:2013:629).

${ }_{53}$ M. Lucas Durán, Subcapitalización e imposición societaria en el País Vasco, 3.

${ }^{54}$ Sentencia del Tribunal Supremo (Sala 3 ${ }^{\mathrm{a}}$ ) de 1 de octubre de 2009, $\mathrm{n}^{\mathrm{o}} 7460 / 2009$ (ECLI:ES:TS:2009:7460). 
La inaplicación del precepto en cuestión condujo a la sustitución de la norma anti-subcapitalización por una limitación a la deducibilidad de los gastos financieros introducida por el Real Decreto Ley 12/2012 ${ }^{55}$. El objetivo de la promulgación de este Real Decreto consistía en la minoración del déficit público en un contexto de debilidad financiera y crisis económica que motivó la utilización de este instrumento legislativo circunscrito a las situaciones de «extraordinaria y urgente necesidad» ${ }^{56}$. La reducción del déficit público pasaba por el incremento de la recaudación, y este fue el móvil que guió la reforma de la Ley del Impuesto sobre Sociedades caracterizada, entre otras cosas, por la modificación y eliminación de deducciones, entre ellas, la limitación a la deducibilidad de gastos financieros. En concreto, se introdujeron dos nuevos límites a la deducibilidad de gastos financieros, uno de aplicación general, contenido en el artículo 16 de la Ley del Impuesto sobre Sociedades, y otro limitado a lo que se ha venido a llamar compraventa apalancada de participaciones o leveraged buyouts, introducido por este Real Decreto como apartado h) del artículo 15 de la Ley del Impuesto de Sociedades. Este régimen, modificado por la Ley 27/2014, del Impuesto sobre Sociedades $^{57}$, es el que está vigente en la actualidad en territorio común.

La Ley 27/2014 se dicta en el marco de la aprobación, el 20 de junio de 2014, de cuatro Anteproyectos de Reforma Fiscal basados en el Informe de la Comisión de Expertos para la Reforma del Sistema Tributario de 5 de julio del año anterior. Tras su promulgación, el régimen de limitación a la deducibilidad de gastos financieros permanece casi inalterado, con la excepción de los apartados 4, sobre los periodos impositivos inferiores a un año y 5 , sobre el leveraged buyout.

\section{EL TRATAMIENTO DE LOS GASTOS FINANCIEROS EN LA LEY 27/2014, DEL IMPUESTO SOBRE SOCIEDADES}

Como se ha mencionado con anterioridad, la regulación actual del tratamiento de los gastos financieros en territorio común establece tres límites, dos regulados en el artículo 16 de la Ley 27/2014, uno general y otro específico para la compraventa apalancada, y otro en el apartado h) del artículo 15

${ }_{55}$ Real Decreto-ley 12/2012, de 30 de marzo, por el que se introducen diversas medidas tributarias y administrativas dirigidas a la reducción del déficit público («BOE» núm. 78, de 31 de marzo de 2012).

56 J. Calvo Vérgez, «La nueva limitación a la deducibilidad de gastos financieros en el Impuesto sobre Sociedades: algunas consideraciones a la luz de la reforma fiscal» en Actum Fiscal $n^{\circ} 95$ (EDA 2015/100069, 2015).

57 Ley 27/2014, de 27 de noviembre, del Impuesto sobre Sociedades («BOE» núm. 288, de 28 de noviembre de 2014). 
del mismo cuerpo legal, aplicable a los gastos financieros derivados de deudas con entidades del grupo, según el artículo 42 del Código de Comercio.

\section{El límite general del artículo 16 de la Ley 27/2014, del Impuesto sobre Sociedades}

El artículo 16 de la Ley 27/2014 prevé la deducibilidad de los gastos financieros netos con el límite del 30 por ciento del beneficio operativo del ejercicio y con un mínimo de 1 millón de euros aplicable a todas las empresas, sin distinguir por razón de la vinculación, de la pertenencia a un grupo de acuerdo al artículo 42 del Código de Comercio o de la procedencia del endeudamiento. Dicho de otra manera, el artículo 16 de la Ley 27/2014 configura una fixed ratio rule complementada con una minimis rule, en consonancia con la Acción 4 de BEPS, que permite que pequeñas y medianas empresas queden de facto al margen de esta limitación. Prevé el precepto, además, la aplicación proporcional de este mínimo para los casos en que el periodo impositivo tenga una duración inferior al año.

En los grupos de consolidación fiscal tanto el ratio fijo como el mínimo de un millón de euros se predicará del conjunto de sociedades integrantes del grupo, si bien no es objeto de este trabajo el tratamiento de esta problemática.

La Dirección General de Tributos, mediante Resolución de 16 de julio de $2012^{58}$, determinó los criterios de interpretación del artículo 16 de la Ley del Impuesto sobre Sociedades, entonces artículo 20, que se exponen en los apartados sucesivos.

A. Gastos financieros e ingresos procedentes de la cesión a terceros de capitales propios

En primer lugar, el apartado primero de la Resolución de la DGT de 16 de julio de 2012 prevé que no deben incluirse los gastos financieros sometidos a otras limitaciones establecidas por la Ley, como los gastos financieros no deducibles del artículo 15.1.h (antes 14.1.h) de la LIS, debiendo considerarse los ajustes resultantes de la aplicación de la normativa sobre precios de transferencia.

Los gastos e ingresos a considerar deben ser partidas homogéneas relacionadas con el endeudamiento empresarial, por lo cual, los gastos financieros a considerar serán aquellos que deriven de las deudas de la entidad tanto con entidades del grupo como con terceros incluidos en las cuentas 661, 662, 664

${ }^{58}$ Resolución de 16 de julio de 2012, de la Dirección General de Tributos, en relación con la limitación en la deducibilidad de gastos financieros en el Impuesto sobre Sociedades («BOE» núm. 170 de 17 de julio de 2012). 
y 665 del modelo de la cuenta de pérdidas y ganancias del Plan General Contable $^{59}$ (PGC). Estas cuentas se refieren a los intereses de obligaciones y bonos, los intereses de deudas, los dividendos de acciones o participaciones consideradas como pasivos financieros o los intereses por descuento de efectos y operaciones de factoring, teniendo en cuenta, de acuerdo con lo establecido por la normativa contable, el efecto de los costes de emisión o de transacción de las operaciones. Incluye los intereses implícitos asociados a las operaciones y las comisiones relacionadas con el endeudamiento empresarial que, de acuerdo con las normas contables, sean parte del importe de los gastos financieros devengados en el periodo impositivo.

Se excluyen los gastos financieros que se incorporen al valor de un activo, los gastos financieros de actualización de provisiones y se prevén una serie de precisiones en relación con otros conceptos contables como el deterioro de valor de créditos, las diferencias de cambio, las coberturas financieras y los contratos de las cuentas en participación.

Por su parte, los ingresos financieros que deben ser tenidos en cuenta son aquellos que proceden de la cesión a terceros de capitales propios, recogidos en las cuentas 761 y 762 del modelo de la cuenta de pérdidas y ganancias del PGC.

\section{B. El beneficio operativo}

El beneficio operativo a efectos de aplicación del artículo 16 se calcula a partir del resultado de explotación de la cuenta de pérdidas y ganancias del ejercicio, que tiene en cuenta amortizaciones, imputación de subvenciones de inmovilizado no financiero y otras, deterioros y resultados de enajenaciones de inmovilizado.

A dicho resultado han de adicionarse los dividendos o participaciones en beneficios de determinadas entidades en las que el porcentaje de participación, directo o indirecto, sea de un mínimo del 5 por ciento o su valor de adquisición supere los 20 millones de euros, salvo que se trate de participaciones adquiridas con deudas cuyos gastos financieros no sean deducibles en virtud del artículo 15.1.h de la LIS y mientras dicha deuda subsista y no haya sido amortizada.

La previsión anterior pretende equiparar el tratamiento de las entidades holding con el resto de entidades para evitar la discriminación de aquellas entidades cuyos dividendos o participaciones en beneficios no se incluyen en el importe neto de la cifra de negocios por realizar actividades distintas de las propias de una holding, cuyo beneficio operativo ya incluye dichos dividendos y participaciones, que no deberá adicionarse.

${ }^{59}$ Real Decreto $1514 / 2007$, de 16 de noviembre, por el que se aprueba el Plan General de Contabilidad («BOE» núm. 278). 


\section{El criterio de imputación temporal}

La regla establecida por el artículo 16 se trata de una regla de ratio fijo que se configura como una regla de imputación temporal o de diferimiento ${ }^{60}$, permitiendo la deducción de los gastos financieros no deducidos en periodos impositivos siguientes mediante los criterios de carry forward of disallowed interest $\mathrm{o}$, simplemente, carry forward y carry back ${ }^{61}$.

Por el criterio carry forward, «los gastos financieros netos que no hayan sido objeto de deducción podrán deducirse en los periodos impositivos siguientes» junto con los gastos financieros netos generados en este periodo y de conformidad con el límite establecido.

Por el sistema carry back, cuando los gastos financieros netos del periodo impositivo no llegan al 30\% del beneficio neto operativo, la diferencia entre este límite y los gastos financieros netos deducidos se adiciona al límite para la deducción de gastos financieros en los periodos impositivos que concluyan en los cinco años inmediatos y sucesivos hasta que dicha diferencia sea efectivamente deducida (apartado 2 del artículo 16).

A esto hacen mención los apartados tercero, cuarto y quinto de la Resolución de la DGT de 16 de julio de 2012. En relación con el criterio carry back la Subdirección General de Ordenación Legal y Asistencia Jurídica de la Agencia Tributaria, en $1 / 15^{62}$, pone de manifiesto la existencia de dos posibles interpretaciones sobre el proceso para arrastrar la diferencia de beneficio operativo pendiente de aplicación.

La primera consiste en interpretar que el límite del beneficio operativo se trata en realidad de un límite acumulado resultante de la adición del 30 por ciento del beneficio operativo del periodo impositivo actual y la diferencia pendiente de deducción de periodos impositivos anteriores dentro del límite de cinco años, entendiéndose el mínimo de 1 millón de euros como mínimo a deducir en el periodo impositivo una vez aplicado el límite acumulado anterior, de suerte que solo cuando los gastos financieros del periodo superen el límite conjunto será de aplicación el mínimo del millón de euros.

La segunda interpretación parte de la premisa de que la diferencia que se arrastra se aplica sobre los gastos financieros netos del periodo impositivo que excedan del límite del 30 por ciento del beneficio operativo y el millón de euros, en lugar de considerar la existencia de un límite acumulado.

${ }^{60}$ L. Suárez de Centi Martínez, V. Viana Barral, «La limitación a la deducibilidad de gastos financieros en el Impuesto sobre Sociedades: Análisis normativo y comentario crítico» en Actualidad Jurídica (Uría \& Menéndez), no 33 (2012).

${ }^{61}$ J. Calvo Vérgez, op. cit., 2.

62 Agencia Tributaria. Subdirección General de Ordenación Legal y Asistencia Jurídica. Nota $\mathrm{n}^{\mathrm{o}} 1 / 15$ relativa a la limitación de gastos financieros prevista en el artículo 16 de la ley $27 / 2014$ de 27 de noviembre. 
La aplicación de una u otra aproximación da lugar a resultados divergentes, considerando la Ordenación Legal y Asistencia Jurídica de la Agencia Tributaria que la primera de las interpretaciones es más acorde con el contenido del artículo 16 y de la interpretación que, de este, hace la Dirección General de Tributos en la Resolución de 16 de julio de 2012 anteriormente citada.

\section{Exclusión del ámbito de aplicación}

De acuerdo con el apartado sexto del artículo 16 de la LIS, esta limitación no será de aplicación a entidades de crédito y aseguradoras. A este respecto, se considera como entidades de crédito también a aquellas entidades cuyos derechos correspondan, directa o indirectamente, a aquellas de forma íntegra, limitándose su actividad a la emisión y colocación en el mercado de instrumentos financieros «para reforzar el capital regulatorio y la financiación de tales entidades», y a los fondos de titulización hipotecaria previstos por la Ley 19/1992, de 7 de julio, sobre Régimen de Sociedades y Fondos de Inversión Inmobiliaria y sobre Fondos de Titulización Hipotecaria, y los fondos de titulización de activos de la Disposición Adicional quinta.2 de la Ley 3/1994, de 14 de abril.

Tampoco se aplica esta limitación en el periodo impositivo en que se extinga la sociedad, salvo que ello traiga su causa de un operación de reestructuración.

\section{La limitación a la deducibilidad de gastos financieros en la compra de acciones apalancada}

El concepto de compra apalancada o leveraged buyout hace referencia a aquella operación por medio de la cual la adquisición de una sociedad financiada con deuda es seguida por la fusión de las entidades adquirente y adquirida, o por la inclusión de la adquirida en el grupo de consolidación fiscal de la adquirente. De esta manera, a pesar de que la sociedad adquirente, que generalmente se trata de una sociedad vehículo sin actividad económica relevante, no generara ingresos suficientes para poderse deducir los gastos financieros incurridos, el elevado beneficio operativo de la adquirida permitía la deducción de los gastos financieros de la deuda contraída para su adquisición ${ }^{63}$.

Para evitar esta situación, el apartado quinto del artículo 16 de la LIS, fruto de la aprobación de la Ley 27/2014 del Impuesto sobre Sociedades, introdujo un nuevo límite a la deducibilidad de gastos financieros en operaciones de compra apalancada o leveraged buyouts, de aplicación cuando una sociedad adquiera las participaciones de otra a través, total o parcialmente, de

${ }^{63}$ R. Fuster Tozer, C. Durán Haeussler, J..., op. cit., 111. 
endeudamiento, cuando en un plazo de cuatro años desde que se produzca dicha adquisición, la sociedad adquirente y adquirida se fusionen o se incorpore la adquirida al grupo de consolidación fiscal de la adquirente.

En este supuesto, los gastos financieros que se hubieran generado como consecuencia del endeudamiento en que incurre la adquirente para la adquisición solo podrán deducirse hasta el límite del 30 por ciento del beneficio operativo de la propia sociedad adquirente. Es decir, para la aplicación del límite no podrán adicionarse los beneficios operativos de adquirente y adquirida para permitir la deducibilidad de los gastos financieros.

Se excluye la aplicación de esta limitación en el periodo impositivo en que se adquieran las participaciones en el capital de entidades si la adquisición se financia con deuda como máximo en un 70 por ciento del precio de adquisición, y en los periodos impositivos siguientes siempre que dicha deuda se minore en, al menos, una cuantía proporcional cada uno de los ocho años siguientes hasta que la deuda alcance el 30 por ciento del precio de adquisición.

\section{La no deducibilidad de gastos financieros en las operaciones intragrupo}

El artículo 15 de la LIS, en su letra h), establece que tendrán el carácter de no deducibles los gastos financieros derivados de deudas con entidades del grupo, según el artículo 42 del Código de Comercio, para la adquisición a otras entidades del mismo de participaciones en el capital o fondos propios de cualquier entidad, o para la realización de aportaciones en el capital o fondos propios de entidades del grupo, salvo que se apreciaren motivos económicos válidos que lo justifiquen.

\section{EL TRATAMIENTO DEL EXCESO DE GASTOS FINANCIEROS EN LA NORMA FORAL DEL IMPUESTO SOBRE SOCIEDADES DE BIZKAIA}

\section{El origen de la regla de subcapitalización en la Norma Foral del Impuesto sobre Sociedades de Bizkaia}

De forma paralela a la normativa de Territorio Común, que entonces era la Ley 43/1995, en el Territorio Histórico de Bizkaia, la Norma Foral 3/1996, de 26 de junio, del Impuesto sobre Sociedades ${ }^{64}$ del Territorio Histórico de Bizkaia adoptó, en su artículo 21, una norma de ratio fijo que imponía la recalificación como dividendos de los intereses devengados cuando el

${ }^{64}$ Norma Foral 3/1996, de 26 de junio, del Impuesto sobre Sociedades («BOB» 11 de julio de 1996). 
endeudamiento neto remunerado de una entidad excediera del resultado de aplicar el coeficiente 3 a la cifra del capital fiscal.

Dicho precepto era de aplicación a entidades no financieras endeudadas con personas o entidades no residentes en el territorio español que tuvieran la consideración de vinculadas.

El apartado tres del artículo 21 permitía la deducibilidad de los intereses cuando se superase dicho ratio fijo si la Administración Tributaria hubiera aprobado la propuesta sometida por el contribuyente para la aplicación de un coeficiente distinto por haberse obtenido el endeudamiento en condiciones normales de mercado. Al igual que en la normativa estatal, el apartado cuarto y último del precepto contemplaba la exclusión de aquellas entidades vinculadas que fueran residentes en otro Estado miembro de la Unión Europea, siempre que no se tratase de un territorio calificado reglamentariamente como paraíso fiscal.

Como consecuencia de los pronunciamientos del TJUE en relación a la compatibilidad de las normas anti-subcapitalización con el principio de no discriminación y las libertades fundamentales, que dieron lugar a la eliminación de la norma anti-subcapitalización en territorio común, los Territorios Históricos, que optaron por el mantenimiento de la regla, debieron abordar una modificación sustancial de su regulación.

\section{La regla de subcapitalización de la Norma Foral 11/2013, del Impuesto sobre Sociedades}

La regla de subcapitalización fue modificada por la Norma Foral 11/2013, del Impuesto sobre Sociedades, vigente a día de hoy, que pasó a regularse en su artículo 47. Conforme al tenor del precepto, se desprenden una serie de condiciones necesarias para su aplicación:

A. La existencia de vinculación entre las entidades prestamista y prestataria

Para la determinación de la vinculación entre las entidades prestamista y prestataria es preciso remitirse al artículo 42.3 de la Norma Foral del Impuesto sobre Sociedades (en adelante, NFIS), que establece los supuestos en los que se considera que una persona o entidad está vinculada a otra. De entre ellos, el caso más frecuente de vinculación es el que nace de la relación por la participación en el capital de otra entidad, siendo suficiente con ostentar al menos el 25 por ciento del capital de la misma.

\section{B. Endeudamiento neto remunerado directo o indirecto}

El endeudamiento, que puede ser directo o indirecto, ha de ser considerado globalmente, en términos netos, en su estado medio a lo largo del 
periodo impositivo y en relación, únicamente, con las entidades vinculadas en los términos anteriormente expuestos.

Por endeudamiento neto hemos de entender aquel que resulta de la diferencia entre los créditos y las deudas de la entidad con las entidades prestamistas vinculadas.

Si bien el endeudamiento directo no genera complejidad alguna, no puede decirse lo mismo del endeudamiento indirecto, concepto indeterminado ${ }^{65}$. Con esta previsión se pretende abordar los denominados back to back loans ${ }^{66}$, supuestos en los que se pretende evitar la aplicación de la norma anti-subcapitalización por la interposición, entre prestamista y prestatario -entidades vinculadas entre sí- de personas o entidades independientes, no vinculadas. A este respecto, para el cálculo del endeudamiento neto remunerado, el Tribunal Supremo, en sentencia de 17 de marzo de $2011^{67}$, determinó que la desvirtuación de la realidad formal alegada por el contribuyente exige que la Administración acredite que concurre la «base y razón de ser de la norma de subcapitalización», es decir, la elusión fiscal.

La doctrina administrativa y la jurisprudencia han realizado una serie de precisiones acerca del tenor literal del artículo 47 en relación con el «endeudamiento neto remunerado, directo o indirecto»:

- Si la entidad prestataria, residente en España, represtara parte del capital recibido en préstamo de una entidad vinculada no residente a otra residente en España vinculada únicamente a la prestataria, para el cálculo del endeudamiento neto remunerado no se descuenta la diferencia entre el préstamo recibido y la parte represtada ${ }^{68}$.

- En caso de aportación de garantía formal y ejecutable por una entidad vinculada no residente sin la cual no se habría concedido el préstamo se considera endeudamiento indirecto ${ }^{69}$, no produciéndose tal calificación en caso de que la entidad no residente no ofreciera garantías formales y concretas, con fuerza ejecutiva, sino solo la confianza generada $^{70}$.

${ }^{65}$ K.M. Castro Arango, «Límites a la capitalización encubierta en España: problemas comunitarios y convencionales de los nuevos artículos 20 y 14.1. h) del TRLIS» en Estudios financieros. Revista de contabilidad y tributación: Comentarios, casos prácticosn ${ }^{\circ}$ 376 (2014), 97-99.

${ }^{66}$ M. Lucas Durán, op.cit., 4.

${ }^{67}$ Sentencia del Tribunal Supremo (Sala $3^{\mathrm{a}}$ ) de 17 de marzo, $\mathrm{n}^{\circ}$ 1825/2011 ( $\mathrm{n}^{\mathrm{o}}$ rec. 5871/2006).

${ }^{68}$ Dirección General de Tributos. Consulta 1615-01, de 4 de septiembre de 2001.

${ }_{69}$ Sentencia del Tribunal Supremo (Sala $3^{\mathrm{a}}$ ) de 17 de marzo, $\mathrm{n}^{\circ} 1825 / 2011\left(\mathrm{n}^{\mathrm{o}}\right.$ rec. 5871/2006).

70 Dirección General de Tributos. Consulta 1210-01, de 20 de junio de 2001. 
La exigencia de que el endeudamiento neto remunerado sea considerado globalmente exige que, de existir más de una entidad prestamista vinculada, el ratio de endeudamiento debe determinarse en relación con todas ellas ${ }^{71}$, salvo que se trate de un grupo en régimen de consolidación fiscal ${ }^{72}$. La exigencia de globalidad se aplica también a la compensación entre créditos y deudas que ha de realizarse para «netear» el endeudamiento.

El cálculo del endeudamiento «en su estado medio» implica la realización de una media aritmética.

Por último, el endeudamiento ha de ser remunerado, lo cual excluye la aplicación del artículo 47 en aquellos casos en que no se devenguen intereses en un préstamo con entidades vinculadas. En caso de endeudamiento presunto (artículo 9 NFIS) o remuneraciones derivadas de ajustes por operaciones vinculadas (artículos 42 y siguientes de la NFIS) corresponde a la Administración probar el carácter remunerado ${ }^{73}$.

Es menester clarificar que los préstamos participativos han de tenerse en cuenta para determinar el endeudamiento medio remunerado con entidades vinculadas no residentes, pero no para el capital fiscal medio, por tener la consideración de recursos ajenos ${ }^{74}{ }^{75}$. Lo mismo puede defenderse respecto de las cuentas en participación u obligaciones convertibles. En términos generales, por tanto, se consideran endeudamiento remunerado todos los instrumentos cuya retribución puede ser deducida; posibilidad que, en el caso de los préstamos participativos, se encuentra en el artículo 31.5 de la NFIS.

\section{Que el importe de dicho endeudamiento supere el resultado de multiplicar por tres el patrimonio neto a efectos fiscales}

El endeudamiento neto remunerado, directo o indirecto, que exceda del ratio previsto por el precepto no tendrá la consideración de deducible, dando, a efectos fiscales, lugar a un ajuste de signo positivo a aplicar en el resultado contable por el importe del exceso.

La cifra del patrimonio neto debe calcularse en su estado medio a lo largo del periodo impositivo. Precisa en su apartado 2 el artículo 47 que se entiende por patrimonio neto a efectos fiscales el importe resultante del balance correspondiente al último día del periodo impositivo que se

${ }^{71}$ C. Palao Taboada, «La subcapitalización», en Fiscalidad internacional por F. Serrano Antón (Dir.), 4a ed., (Madrid: CEF, 2010), 1009.

72 Dirección General de Tributos. Consulta 1315-98, de 20 de julio de 1998.

73 M. Lucas Durán, op. cit., 4.

${ }^{74}$ Dirección General de Tributos. Consulta 2055-97, de 9 de octubre de 1997.

${ }^{75}$ Boletín Oficial del Instituto de Contabilidad y Auditoría de Cuentas. Consulta $\mathrm{n}^{\mathrm{o}} 1$, $\mathrm{n}^{\text {o }}$ de BOICAC 78/junio 2009. 
corresponda con los fondos propios de acuerdo al Plan General Contable. Ello genera una incoherencia, pues el importe de patrimonio neto en su estado medio no tiene por qué coincidir. Ante esta problemática, algunos autores optan por la aplicación del criterio más favorable al contribuyente por analogía con el artículo 1288 del Código $\mathrm{Civil}^{76}$ en relación con la interpretación de cláusulas oscuras ${ }^{77}$. El patrimonio neto es un concepto contable que, de acuerdo con el PGC, se integra por la suma el capital, la prima de emisión, las reservas, los resultados de ejercicios anteriores, otras aportaciones de socios, el resultado del ejercicio y otros instrumentos de patrimonio neto, a lo cual se sustrae el importe de las acciones y participaciones en patrimonio propias y el dividendo a cuenta. Sin embargo, a los efectos del artículo 47, no debe incluirse en la cifra de patrimonio neto el importe del resultado del ejercicio.

\section{Supuestos de exclusión}

El precepto excluye expresamente de la aplicación de la norma de subcapitalización a las entidades financieras en cuanto entidades prestamistas por excelencia.

Se excluye, asimismo, la aplicación de la norma de subcapitalización cuando el endeudamiento neto remunerado del contribuyente no exceda de los 10 millones de euros en ningún momento del periodo.

Por otro lado, no se aplicará a los contribuyentes a los que se aplique la limitación a la deducibilidad establecida en el artículo 25.bis NFIS que se expone a continuación.

\section{E. Posibilidad de evitar la aplicación del artículo}

Establece el apartado cuatro del artículo 47 que los contribuyentes pueden someter a la Administración tributaria una propuesta para aplicar un coeficiente distinto al establecido en el apartado uno del precepto, basándose en que el endeudamiento mantenido con personas o entidades vinculadas lo hubieran podido obtener en condiciones normales de mercado con entidades no vinculadas, en atención al principio arm 's length.

Ello no será de aplicación a operaciones con personas o entidades residentes en países o territorios considerados como paraísos fiscales.

${ }^{76}$ Real Decreto de 24 de julio de 1889 por el que se publica el Código Civil («BOE» núm. 206, de 25 de julio de 1889).

77 GOROSPE OVIEDO, J. I. y HERRERA MOLINA, P. M. (2001), «La interpretación favorable al contribuyente ante la oscuridad normativa», Crónica Tributaria núm. 100, citado en LUCAS DURÁN, M. op. cit., p. 6. 


\section{Efectos del artículo 47 de la Norma Foral del Impuesto sobre Sociedades}

El artículo 47 prevé que si el endeudamiento neto remunerado, directo o indirecto, de una entidad con persona o entidad vinculada excediera del resultado de multiplicar por 3 el importe de su patrimonio neto a efectos fiscales, los intereses devengados correspondientes al exceso tendrán la consideración de dividendos. Dado que, contablemente, el resultado estará minorado por la totalidad del gasto financiero devengado, deberá procederse a incrementar el beneficio contable de cara a obtener la base imponible en el importe que, de acuerdo a la regla expuesta, resulte no deducible ${ }^{78}$. En el supuesto de que la recalificación sea realizada por la Administración Tributaria en un procedimiento de comprobación implicará, además, intereses de demora o sanciones. En definitiva, la aplicación del artículo 47 implica un incremento en la base imponible de la sociedad a la que el mismo se aplique.

Sin embargo, pueden identificarse otras consecuencias jurídicas relevantes derivadas de la aplicación del precepto, que se plasman tanto en el ámbito interno como en el internacional.

Por un lado, en el ámbito interno, la recalificación puede traer consigo efectos también en sede de la prestamista porque, de acuerdo con el artículo 33 NFIS $^{79}$, no se integrarán en su base imponible los dividendos en el supuesto de que «la participación, directa o indirecta, en el capital o en los fondos propios de la entidad que reparte el dividendo sea, al menos, del 5 por 100 , o del 3 por 100 si las acciones de la sociedad participada cotizan en un mercado secundario organizado».

En el ámbito internacional, en sede del prestatario o pagador de los intereses, además de la no deducibilidad de los intereses pagados, habrá de retener un 19 por ciento tanto si se califican como dividendos como si se califican como intereses ${ }^{80}$. Sin embargo, podría darse la situación de que ese pago estuviera exento en caso de estar al amparo de la Directiva 2011/96/UE del Consejo, de 30 de noviembre de $2011^{81}$, que contempla la exención de los dividendos matriz-filial intraeuropeos o al amparo de los dispuesto por el

\footnotetext{
${ }_{78}$ M. Lucas Durán, op. cit., 8.

79 También en el artículo 33 de la Norma Foral 37/2013, de 13 de diciembre, del Impuesto sobre Sociedades del Territorio Histórico de Álava; y de la Norma Foral 2/2014, de 17 de enero, sobre el Impuesto de Sociedades del Territorio Histórico de Gipuzkoa.

${ }^{80}$ Artículo 25.1.f) de la Norma Foral 12/2013 de 5 de diciembre (Bizkaia), del Impuesto sobre la Renta de no Residentes («BOB» de 13 de diciembre de 2013).

${ }^{81}$ Directiva 2011/96/UE del Consejo de 30 de noviembre de 2011 relativa al régimen fiscal común aplicable a las sociedades matrices y filiales de Estados miembros diferentes («DOUE» L 345/8, de 29 de diciembre de 2011).
} 
Convenio para evitar la Doble Imposición correspondiente, que podrá establecer un porcentaje de retención diferente.

En sede del prestamista, puede darse la situación de que el Estado de residencia de este otorgue un tratamiento diferente a la operación de recalificación. De esta manera, si bien el OECD Thin Capitalization Report de 1987 preveía la obligación del Estado de residencia de aceptar la recalificación operada por el Estado de la fuente si esta fuese conforme al artículo 9 del Modelo Convenio de la OCDE, pueden subsistir controversias que deben ser solucionadas conforme al procedimiento de mutuo acuerdo del Convenio para la Doble Imposición correspondiente o el Convenio Europeo de arbitraje $\mathrm{e}^{82}$.

\section{La limitación a la deducibilidad de gastos financieros en la Norma Foral 11/2013}

Los Territorios Históricos han ido adaptando su normativa a las exigencias internacionales derivadas tanto del plan BEPS como de las Directivas Europeas, con soluciones similares. De esta manera, en los tres Territorios se han incorporado nuevas disposiciones que permiten «cumplir con las obligaciones derivadas del marco fiscal impulsado en los foros internacionales como la OCDE y la Unión Europea, en los ámbitos de la prevención de la elusión fiscal, la erosión de las bases imponibles y el traslado artificioso de los beneficios empresariales $\rangle^{83}$. Ejemplo de esta adaptación es la Norma Foral 2/2018 (Bizkaia), de 21 de marzo ${ }^{84}$ que, para luchar contra la elusión fiscal, aprovechando para trasponer e incorporar al ordenamiento tributario foral la Directiva anti-abuso de la Unión Europea, introduce modificaciones, entre otros, en la Norma Foral del Impuesto sobre Sociedades.

En concreto, la reforma operada por la Norma Foral 2/2018 en la Norma Foral del Impuesto sobre Sociedades de Bizkaia, aplicable a los periodos impositivos iniciados desde el 1 de enero de 2018, incorpora en el nuevo

82 90/436/CEE: Convenio relativo a la supresión de la doble imposición en caso de corrección de los beneficios de empresas asociadas - Acta final - Declaraciones conjuntas - Declaraciones unilaterales. («DOUE» L 225, de 20 de octubre de 1990).

${ }^{83}$ I. Merino Jara, op. cit., 4.

${ }^{84}$ NORMA FORAL 2/2018, de 21 de marzo, por la que se caracterizan a efectos tributarios determinados fondos de inversión a largo plazo europeos y se introducen modificaciones en las Normas Forales del Impuesto sobre la Renta de las Personas Físicas, del Impuesto sobre Patrimonio, del Impuesto sobre Sociedades, del Impuesto sobre Transmisiones Patrimoniales y Actos Jurídicos Documentados, del Impuesto sobre Sucesiones y Donaciones y del Régimen fiscal de Cooperativas, así como en la Norma Foral General Tributaria del Territorio Histórico de Bizkaia («BOB» núm. 61 de 27 de marzo de 2018). 
artículo 25.bis de la Norma Foral del Impuesto sobre Sociedades ${ }^{85}$, un nuevo esquema de limitación a la deducibilidad de gastos financieros, el cual, de acuerdo con la Exposición de Motivos de la norma de 2018, permite su deducibilidad hasta 3 millones de euros, exonerando a las entidades que no integren un grupo y a los grupos que considere saneados desde la óptica del endeudamiento ${ }^{86}$, de conformidad con los dispuesto en la Directiva pero difiriendo de la regulación prevista en territorio común. Además, esta reforma introduce un inciso al artículo 47, que regula la compatibilidad del esquema de subcapitalización y el nuevo esquema de limitación a la deducibilidad de gastos financieros, lo cual ha generado problemas de aplicación que se tratarán más adelante.

Este precepto, de conformidad con la Directiva, establece un ratio fijo de gastos financieros netos deducibles limitado al 30 por ciento del beneficio operativo, entendiendo como tales, al igual que en la normativa de territorio común, aquellos gastos financieros que exceden de los ingresos derivados de la cesión de capitales propios a terceros en el periodo impositivo, excluyendo los no deducibles del artículo 31 de la Norma Foral.

El procedimiento para la determinación del beneficio operativo coincide parcialmente con el establecidos en la normativa estatal, pues si bien parte asimismo del resultado de explotación de la cuenta de pérdidas y ganancias del ejercicio eliminando la amortización del inmovilizado, la imputación de subvenciones de inmovilizado no financiero y otras, el deterioro y resultado de enajenaciones de inmovilizado y adiciona los ingresos financieros de participaciones en instrumentos de patrimonio correspondientes a dividendos o participaciones en beneficios de entidades en las que la participación directa o indirecta sea de al menos un 5 por ciento, 3 por ciento si las acciones de la sociedad cotizan en un mercado secundario organizado, especialidad, esta última, que no comparte la norma estatal. Explicita este artículo que no formarán parte del beneficio operativo ingresos y gastos no integrados en la base imponible del impuesto.

La Norma Foral eleva el umbral mínimo deducible de un millón de euros, en Territorio Común, a tres millones de euros por periodo impositivo de un año o la cantidad proporcional si el periodo fuera inferior, que serán deducibles en todo caso, lo que permite exonerar de esta limitación al pequeño contribuyente, de acuerdo con la Directiva.

El artículo 25.bis, en su apartado sexto, excluye de su ámbito de aplicación a las entidades de crédito y aseguradoras, así como en el periodo

${ }^{85}$ Norma Foral 11/2013, de 5 de diciembre, del Impuesto sobre Sociedades («BOB» de 13 diciembre de 2013).

86 A. Pérez Delgado, «Modificaciones en la BI de la Directiva contra la elusión fiscal» en Foro Aranzadi. Thomson Reuters Formación. 
impositivo en que se extinga la entidad salvo que ello sea consecuencia de una operación de reestructuración, en los mismos términos que la Ley del Impuesto sobre Sociedades. Sin embargo, la Norma Foral añade un supuesto de exoneración para aquellas entidades «que no formen parte de un grupo de sociedades de acuerdo al artículo $42^{87}$ del Código de Comercio, no se encuentren vinculadas con otras entidades de conformidad con lo dispuesto en el artículo 42 de esta Norma Foral y no tengan ningún establecimiento permanente en el extranjero». Dicho de otra manera, a diferencia de la normativa estatal, que se aplica sin distinguir por razón de la vinculación, de la pertenencia a un grupo de acuerdo al artículo 42 del Código de Comercio o de la procedencia del endeudamiento, la norma foral opta por limitar su ámbito de aplicación.

La Directiva preveía la posibilidad de que los Estados permitieran una deducción que excediera del límite de acuerdo con las magnitudes del grupo empresarial del contribuyente, bien en base a ratios de activo frente a patrimonio neto, bien en base a la proporción entre los gastos financieros netos del grupo frente a terceros no vinculados y el EBITDA del mismo ${ }^{88}$. De conformidad con lo anterior, la norma foral provee al contribuyente de dos alternativas.

Por un lado, permite que el contribuyente que forme parte de un grupo de acuerdo al artículo 42 del Código de Comercio, demuestre que la proporción existente entre sus fondos propios y el total de sus activos es igual o superior a la equivalente del grupo siempre y cuando la valoración de los activos y pasivos siga el mismo método que el aplicado a los estados financieros consolidados elaborados conforme a las Normas para la Formulación de Cuentas Anuales Consolidadas, aprobadas por el Real Decreto 1159/2010, de 17 de septiembre. A este respecto, aclara el precepto en su apartado 7 que la proporción o razón entre los fondos propios del contribuyente y el total de sus activos es igual a la equivalente del grupo «si la razón entre los fondos propios del contribuyente y el total de sus activos es inferior en dos puntos porcentuales como máximo a aquélla».

${ }^{87}$ De acuerdo al artículo 42 del Código de Comercio (Real Decreto de 22 de agosto de 1885 por el que se publica el Código de Comercio. «BOE» núm. 289, de 16 de octubre de 1885) «existe un grupo cuando una sociedad ostente o pueda ostentar, directa o indirectamente, el control de otra u otras», más en particular, cuando una sociedad posea la mayoría de los derechos de voto de otra, tenga facultad de nombrar o destituir a la mayoría de los miembros del órgano de administración, pueda disponer de la mayoría de los derechos de voto o haya designado con sus votos a la mayoría de los miembros del órgano de administración que desempeñen su cargo en el momento en que deban formularse las cuentas consolidadas y durante los dos ejercicios inmediatamente anteriores.

${ }^{88}$ I. Alonso Arce, «La limitación a la deducibilidad de gastos financieros en el Impuesto sobre Sociedades» en Forum Fiscal n 243, (junio 2018), 2. 
Por otro lado, permite la Norma Foral, en el apartado octavo del artículo 25.bis, que el contribuyente integrante de un grupo someta a la Administración Tributaria una propuesta para aplicar un límite a la deducibilidad de gastos financieros netos superior al 30 por ciento en base al coeficiente de los gastos financieros netos del grupo frente a terceros sobre el beneficio operativo del grupo, quedando supeditada la aplicación de la proporción del grupo a la obtención de un procedimiento de vinculación administrativa que admita su aplicación.

Por último, en trasposición de la directiva y en términos coincidentes con la normativa estatal, la norma foral prevé un criterio de imputación temporal que permite trasladar al futuro tanto los gastos financieros netos no deducidos como la diferencia resultante entre los gastos financieros neto deducidos y el resultado de calcular el 30 por ciento del beneficio operativo del periodo impositivo o el coeficiente superior autorizado por la Administración conforme a lo expuesto. Así, en el caso de que los gastos financieros de un periodo impositivo no alcanzaran el límite del 30 por 100 «se adicionarán al límite del 30 por 100 para la deducción de gastos financieros netos en los periodos impositivos que concluyan en los 5 años inmediatos y sucesivos, hasta que se deduzca dicha diferencia». Por otro lado, los gastos financieros que no hubieran podido deducirse, por exceder del límite del 30 por 100 , podrán deducirse en los periodos impositivos siguientes junto con los del periodo correspondiente, con el límite del 30 por 100 del beneficio operativo del ejercicio en cuestión, dando lugar a un ajuste negativo en la base imponible. En último caso, los gastos financieros no deducidos podrán deducirse en el periodo de extinción de la entidad salvo que esta sea consecuencia de una operación de reestructuración.

De esta manera, se aprecia la conformidad de la Norma Foral con lo dispuesto por la directiva anti-abuso de la Unión Europea de conformidad con las especialidades forales y el principio de proporcionalidad ${ }^{89}$.

${ }^{89}$ I. Alonso Arce, op. cit., 3. 


\begin{tabular}{|l|r|r|r|}
\hline \multicolumn{1}{|c|}{ Aplicación del ratio fijo y la minimis rule } & \multicolumn{1}{c|}{ Caso 1 } & \multicolumn{1}{c|}{ Caso 2 } & \multicolumn{1}{c|}{ Caso 3 } \\
\hline Gastos financieros & $4.096 .466,00$ & $8.655 .107,00$ & $17.020 .669,00$ \\
\hline Ingresos financieros & 0,00 & $509.000,00$ & $3.077,00$ \\
\hline Gastos financieros netos & $4.096 .466,00$ & $8.146 .107,00$ & $17.017 .592,00$ \\
\hline
\end{tabular}

\begin{tabular}{|c|c|c|c|}
\hline Resultado de explotación & $4.224 .590,00$ & $17.895 .166,00$ & $27.444 .439,00$ \\
\hline Amortización inmovilizado $(+)$ & $1.532 .638,00$ & $656.690,00$ & $3.696,00$ \\
\hline $\begin{array}{l}\text { Imputación de subvenciones del } \\
\text { inmovilizado }(-)\end{array}$ & & $253.000,00$ & \\
\hline $\begin{array}{l}\text { Deterioro y resultado por enajenaciones } \\
\text { del inmovilizado }(+/-)\end{array}$ & & & \\
\hline $\begin{array}{l}\text { Dividendos de entidades participantes en } \\
\text { al menos un } 5 \% \text { o } 3 \% \text { (cotizada) }(+)\end{array}$ & & & \\
\hline $\begin{array}{l}\text { Ingresos incluidos en las magnitudes } \\
\text { anteriores si están exentos }(-)\end{array}$ & & & \\
\hline $\begin{array}{l}\text { Gastos incluidos en las magnitudes } \\
\text { anteriores si no son deducibles }(+)\end{array}$ & & $2.931 .121,00$ & \\
\hline Beneficio operativo fiscal & $5.757 .228,00$ & $21.229 .977,00$ & $27.448 .135,00$ \\
\hline 30 por 100 del beneficio operativo fiscal & $1.727 .168,40$ & $6.368 .977,00$ & $8.234 .440,50$ \\
\hline Mínimos de 3 millones de euros & $3.000 .000,00$ & $3.000 .000,00$ & $3.000 .000,00$ \\
\hline Gastos financieros netos deducibles & $3.000 .000,00$ & $6.368 .993,10$ & $8.234 .440,50$ \\
\hline Gastos financieros netos no deducibles & $1.096 .466,00$ & $1.777 .113,90$ & $8.783 .151,50$ \\
\hline
\end{tabular}

Fuente: PÉREZ DELGADO, A. «Modificaciones en la BI de la Directiva contra la elusión fiscal». Foro Aranzadi. Thomson Reuters Formación. 


\begin{tabular}{|l|r|r|r|}
\hline \multicolumn{1}{|c|}{ Imputación temporal } & \multicolumn{1}{c|}{ Período 1 } & \multicolumn{1}{c|}{ Período 2 } & \multicolumn{1}{c|}{ Período 3 } \\
\hline Gastos financieros & $9.523 .451,00$ & $6.458 .210,00$ & $8.548 .027,00$ \\
\hline Ingresos financieros & $3.077,00$ & $4.550,00$ & $2.304,00$ \\
\hline Gastos financieros netos & $9.520 .374,00$ & $6.453 .660,00$ & $8.545 .723,00$ \\
\hline
\end{tabular}

\begin{tabular}{|l|r|r|r|}
\hline Resultado de explotación & $27.444 .439,00$ & $29.532 .043,00$ & $26.045 .098,00$ \\
\hline Amortización inmovilizado (+) & $3.696,00$ & $4.512,00$ & $2.379,00$ \\
\hline $\begin{array}{l}\text { Imputación de subvenciones del } \\
\text { inmovilizado (-) }\end{array}$ & & & \\
\hline $\begin{array}{l}\text { Deterioro y resultado por enajenaciones } \\
\text { del inmovilizado (+/-) }\end{array}$ & & & \\
\hline $\begin{array}{l}\text { Dividendos de entidades participantes en } \\
\text { al menos un 5\% o 3\% (cotizada) (+) }\end{array}$ & & & \\
\hline $\begin{array}{l}\text { Ingresos incluidos en las magnitudes } \\
\text { anteriores si están exentos (-) }\end{array}$ & & & \\
\hline $\begin{array}{l}\text { Gastos incluidos en las magnitudes } \\
\text { anteriores si no son deducibles (+) }\end{array}$ & & & \\
\hline Beneficio operativo fiscal & $27.448 .135,00$ & $29.536 .555,00$ & $26.042 .719,00$ \\
\hline
\end{tabular}

\begin{tabular}{|l|r|r|r|}
\hline 30 por 100 del beneficio operativo fiscal & $8.234 .440,50$ & $8.860 .966,50$ & $7.812 .815,70$ \\
\hline Mínimos de 3 millones de euros & $3.000 .000,00$ & $3.000 .000,00$ & $3.000 .000,00$ \\
\hline Gastos financieros netos deducibles & $8.234 .440,50$ & $6.453 .660,00$ & $7.812 .815,70$ \\
\hline $\begin{array}{l}\text { Gastos financieros netos no deducibles } \\
\text { (ajuste positivo en base imponible) }\end{array}$ & $1.285 .933,50$ & 0,00 & \\
\hline $\begin{array}{l}\text { Gastos financieros no deducidos de un } \\
\text { período anterior a deducir en este período } \\
\text { (ajuste negativo en base imponible) }\end{array}$ & 0,00 & $1.285 .933,50$ & \\
\hline $\begin{array}{l}\text { Diferencia entre el 30 por 100 del } \\
\text { beneficio operativo fiscal y los gastos } \\
\text { financieros netos deducidos }\end{array}$ & 0,00 & $1.121 .373,00$ & \\
\hline $\begin{array}{l}\text { Gastos financieros que se deducen } \\
\text { aprovechando esa diferencia positiva }\end{array}$ & 0,00 & 0,00 & $732.907,30$ \\
\hline $\begin{array}{l}\text { Diferencia entre el 30 por 100 del } \\
\text { beneficio operativo fiscal y los gastos } \\
\text { financieros deducidos }\end{array}$ & & & $388.465,70$ \\
\hline
\end{tabular}

Fuente: PÉREZ DELGADO, A. «Modificaciones en la BI de la Directiva contra la elusión fiscal». Foro Aranzadi. Thomson Reuters Formación. 


\section{El doble límite del artículo 47 de la Norma Foral del Impuesto sobre Sociedades y su conciliación con el artículo 25.bis}

La reforma operada por la Norma Foral 2/2018 en la Norma Foral del Impuesto sobre Sociedades de Bizkaia incorpora un nuevo esquema de limitación a la deducibilidad de gastos financieros, el cual, a diferencia de lo que ocurrió en el Territorio Común y en la Comunidad Foral de Navarra con la reforma operada por el Real Decreto-ley 12/2012, de 30 de marzo y la Ley Foral navarra 21/2012, de 26 de diciembre, respectivamente, coexiste con la regla de subcapitalización del artículo 47 de la Norma Foral para aquellas entidades a las que no afecta la limitación de gastos financieros, complementándose con ella en lugar de sustituyéndola ${ }^{90}$.

En este sentido, la Norma Foral 2/2018 introdujo un nuevo inciso en el artículo 47 a tenor del cual la regla de subcapitalización no será de aplicación a aquellos contribuyentes a los que aplique la limitación a la deducibilidad de gastos financieros establecida en el artículo 25.bis.

Sin embargo, en la práctica, surgen dudas interpretativas acerca de este inciso que repercuten directamente en su aplicación. La disyuntiva subyace sobre la interpretación de la frase que determina que el artículo 47 no será de aplicación «a los que se aplique la limitación a la deducibilidad de gastos financieros». Así, se plantean tres principales opciones:

1. El artículo 47 es aplicable siempre y cuando no proceda la realización de ajuste positivo conforme al 25.bis.

2. El artículo 47 es aplicable solo y únicamente cuando, además de no proceder realización de ajuste positivo conforme al 25.bis, no se registren gastos financieros superiores a tres millones de euros.

3. El artículo 47 es únicamente aplicable a los supuestos expresamente excluidos del artículo 25.bis, enumerados en su apartado sexto.

Dada la novedad del precepto y, con ello, de la problemática suscitada, aún no han recaído pronunciamientos al respecto, si bien sí se han emitido diversas opiniones.

En opinión de ALONSO ARCE ${ }^{91}$, subdirector de Coordinación y Asistencia Técnica de la Hacienda Foral de Bizkaia, se deberá abordar primero la determinación de la procedencia de limitación a la deducibilidad de gastos financieros de acuerdo con el artículo 25.bis de suerte que, si esta no procede, se aplicará la norma anti-subcapitalización enunciada en el artículo 47 de la NFIS. No obstante, de haber sido corregido el resultado

${ }^{90}$ MEMENTO FISCAL. «Limitación de la deducibilidad de los gastos financieros». 2016.

${ }^{91}$ I. Alonso Arce, op. cit., 3. 
contable conforme a la regla de limitación a la deducibilidad de gastos financieros, no procederá la aplicación del artículo 47. Esta interpretación parece responder a la primera de las alternativas planteadas, en virtud de la cual la regla de subcapitalización es aplicable siempre y cuando no proceda ajuste conforme al 25.bis.

Sin embargo, PÉREZ DELGADO, Subdirector de Inspección de Hacienda Foral de Bizkaia, con motivo de su presentación «Modificaciones en la BI derivadas de la Directiva contra la elusión fiscal» en el marco del Foro Aranzadi, manifestó, como «criterio no oficial» que podían concurrir tres supuestos:

1. Sociedad con ajuste positivo en virtud del 25.bis: no tendrá que hacer análisis de subcapitalización.

2. Sociedad sin ajuste positivo en virtud del 25.bis con gastos financieros netos superiores a tres millones de euros: no tendrá que hacer análisis de subcapitalización.

3. Sociedad sin ajuste positivo en virtud del 25.bis con gastos financieros inferiores a tres millones de euros: sí tendrá que hacer análisis de subcapitalización.

De esta manera, conforme a la segunda de las alternativas interpretativas expuestas, solo procederá análisis de subcapitalización conforme al artículo 47 cuando la sociedad que no hubiera debido hacer ajuste positivo tenga unos gastos financieros inferiores a los tres millones de euros.

\begin{tabular}{|l|c|c|c|}
\hline \multicolumn{1}{|c|}{ El doble límite de la Norma Foral 11/2013 } & Caso 1 & Caso 2 & Caso 3 \\
\hline Gastos Financiero Neto & $4.000 .000,00$ & $2.000 .000,00$ & $4.000 .000,00$ \\
\hline 30 por 100 b operativo & $3.000 .000,00$ & $3.000 .000,00$ & $6.000 .000,00$ \\
\hline Minimis rule & $3.000 .000,00$ & $3.000 .000,00$ & $3.000 .000,00$ \\
\hline Deducible & $3.000 .000,00$ & $2.000 .000,00$ & $4.000 .000,00$ \\
\hline Ajuste Positivo en base imponible (25.bis) & $1.000 .000,00$ & No & No \\
\hline Subcapitalización (criterio 1) & No procede & Sí procede & Sí procede \\
\hline Subcapitalización (criterio 2) & No procede & Sí procede & No procede \\
\hline
\end{tabular}

Fuente: Elaboración propia.

\section{CONCLUSIÓN}

Todo lo expuesto en este trabajo responde a la necesidad de abordar la problemática de la erosión de las bases imponibles mediante el traslado de 
beneficios gracias a la utilización de lagunas y mecanismos entre los distintos sistemas impositivos de los que se valen las empresas y, más en concreto, las empresas multinacionales, lo cual se ha visto favorecido por la globalización y la creciente movilidad del capital ${ }^{92}$.

La problemática del tratamiento de los gastos financieros como instrumento básico de la política fiscal agresiva se encuentra en constante evolución hacia una creciente armonización, con BEPS como piedra angular, que ha influido en la esfera legislativa comunitaria y nacional, sirviendo de orientación para los distintos ordenamientos jurídicos.

La implementación de sus recomendaciones ha encontrado eco tanto a nivel comunitario como a nivel español, en territorio común y foral, si bien, sin embargo, dicha respuesta, aunque similar, no ha sido plenamente coincidente, como podemos ver en la tabla comparativa siguiente. La diferencia primordial es la minimis rule, que en el País Vasco se ha configurado con el máximo previsto por la Directiva europea (tres millones de euros), optándose, en territorio común, por una cifra más reducida de un millón de euros. En parte por ello, la regulación foral resulta atractiva para la inversión en el País Vasco si bien también presenta debilidades: por un lado, la dificultad de prueba del endeudamiento indirecto y la relativa facilidad para ser sorteada mediante estructuras complejas, en cuyo caso podrá aplicarse el artículo 14 de la Norma Foral 2/2005 General Tributaria de Bizkaia ${ }^{93}$, que recoge una cláusula anti-elusión genérica.

La globalización y el dinamismo de la economía impulsan a los operadores económicos a diseñar nuevas fórmulas de financiación y estructuras financieras con el objeto de reducir su carga fiscal como medio para incrementar sus beneficios, aprovechándose de las lagunas y discordancias entre las normas tributarias de los Estados. El legislador debe estar alerta para abordar y reaccionar frente a los retos que esta situación supone, estableciendo los mecanismos oportunos para evitar la erosión de bases imponibles y el traslado de beneficios por vía de deducción de intereses y otros gastos financieros, consecuencia de dichas lagunas y discordancias, siendo necesaria una mayor coordinación entre los sistemas fiscales nacionales.

En definitiva, la regulación de la deducibilidad de los gastos financieros en el Impuesto sobre Sociedades es clave en la lucha contra la erosión de bases imponibles y, como tal, se encuentra a la orden del día de la práctica legislativa y jurídica tanto a nivel comunitario, como estatal como foral. Se

${ }^{92}$ OCDE. «10 preguntas sobre BEPS» https://www.oecd.org/ctp/10-preguntas-sobrebeps.pdf (Última consula 21 de abril de 2019).

${ }_{93}$ NORMA FORAL 2/2005, de 10 de marzo, General Tributaria del Territorio Histórico de Bizkaia («BOB» de 11 marzo) de 2015. 
caracteriza por estar en constante adaptación a la realidad social, económica y política, lo cual se ha visto recientemente reflejado en la reforma operada en 2018 en los territorios forales. Suscita diversas problemáticas cuyo análisis excede del objeto de este trabajo pero que, sin lugar a dudas, darán lugar a pronunciamientos judiciales y administrativos que continuarán dando forma al régimen legal de la deducibilidad de los gastos financieros, como en el caso de la conciliación de los límites de los artículos 25.bis y 47 de la Norma Foral de Bizkaia.

\begin{tabular}{|c|c|c|c|}
\hline & $\begin{array}{l}\text { Directiva (UE) } \\
\text { 2016/1164 }\end{array}$ & $\begin{array}{l}\text { Ley Impuesto sobre } \\
\text { sociedades }\end{array}$ & $\begin{array}{l}\text { Norma Foral } \\
\text { Impuesto sobre } \\
\text { Sociedades }\end{array}$ \\
\hline Ratio fijo & $\begin{array}{l}30 \text { por ciento del } \\
\text { EBITDA }\end{array}$ & $\begin{array}{c}30 \text { por ciento del } \\
\text { beneficio operativo }\end{array}$ & $\begin{array}{c}30 \text { por ciento del } \\
\text { beneficio operativo }\end{array}$ \\
\hline Beneficio operativo & EBITDA & \begin{tabular}{|c} 
EBITDA \\
(el porcentaje de \\
participación exigido \\
para adicionar los \\
ingresos financieros \\
de participaciones en \\
instrumentos de \\
patrimonio es del 5 \\
por 100)
\end{tabular} & $\begin{array}{c}\text { EBITDA } \\
\text { (el porcentaje de } \\
\text { participación exigido } \\
\text { para adicionar los } \\
\text { ingresos financieros } \\
\text { de participaciones en } \\
\text { instrumentos de } \\
\text { patrimonio es del } 5 \\
\text { por } 100,3 \text { por } 100 \text { si } \\
\text { las acciones de la } \\
\text { sociedad participada } \\
\text { cotizan en el } \\
\text { mercado secundario) }\end{array}$ \\
\hline $\begin{array}{l}\text { Mínimo deducible } \\
\text { (en euros) }\end{array}$ & Hasta 3.000 .000 & 1.000 .000 & 3.000 .000 \\
\hline $\begin{array}{l}\text { Aplicación a } \\
\text { entidades aisladas }\end{array}$ & $\begin{array}{l}\text { Posibilidad de } \\
\text { deducción íntegra } \\
\text { para entidades } \\
\text { aisladas }\end{array}$ & $\begin{array}{l}\text { Aplicación de la } \\
\text { limitación a la } \\
\text { deducibilidad a } \\
\text { entidades aisladas }\end{array}$ & $\begin{array}{l}\text { No aplicación de la } \\
\text { limitación a la } \\
\text { deducibilidad a } \\
\text { entidades aisladas }\end{array}$ \\
\hline Carry forward & \begin{tabular}{|c|} 
Posibilidad de fijar \\
normas para traspasar \\
a un período \\
posterior, sin \\
limitación temporal, \\
costes de \\
endeudamiento \\
excedentarios que no \\
han podido deducirse
\end{tabular} & \begin{tabular}{|c|} 
Los gastos no \\
deducidos pueden \\
deducirse en los \\
períodos impositivos \\
siguientes
\end{tabular} & $\begin{array}{c}\text { Los gastos no } \\
\text { deducidos pueden } \\
\text { deducirse en los } \\
\text { períodos impositivos } \\
\text { siguientes }\end{array}$ \\
\hline
\end{tabular}




\begin{tabular}{|c|c|c|c|}
\hline & $\begin{array}{c}\text { Directiva (UE) } \\
\text { 2016/1164 }\end{array}$ & $\begin{array}{l}\text { Ley Impuesto sobre } \\
\text { sociedades }\end{array}$ & $\begin{array}{l}\text { Norma Foral } \\
\text { Impuesto sobre } \\
\text { Sociedades }\end{array}$ \\
\hline Carry back & $\begin{array}{l}\text { Posibilidad de fijar } \\
\text { normas para traspasar } \\
\text { a un período } \\
\text { posterior la } \\
\text { capacidad no } \\
\text { utilizada de deducir } \\
\text { intereses hasta un } \\
\text { máximo de } 5 \text { años }\end{array}$ & $\begin{array}{l}\text { La diferencia entre el } \\
30 \text { por } 100 \text { del } \\
\text { beneficio operativo y } \\
\text { los gastos financieros } \\
\text { netos del período se } \\
\text { adiciona al límite del } \\
30 \text { por } 100 \text { para } \\
\text { deducción de gastos } \\
\text { financieros netos en } \\
\text { los períodos que } \\
\text { concluyan en los } 5 \\
\text { años inmediatos y } \\
\text { sucesivos }\end{array}$ & $\begin{array}{l}\text { La diferencia entre el } \\
30 \text { por } 100 \text { del } \\
\text { beneficio operativo y } \\
\text { los gastos financieros } \\
\text { netos del período se } \\
\text { adiciona al límite del } \\
30 \text { por } 100 \text { para } \\
\text { deducción de gastos } \\
\text { financieros netos en } \\
\text { los períodos que } \\
\text { concluyan en los } 5 \\
\text { años inmediatos y } \\
\text { sucesivos }\end{array}$ \\
\hline $\begin{array}{l}\text { Exclusión de } \\
\text { sociedades } \\
\text { financieras }\end{array}$ & $\begin{array}{l}\text { Posibilidad de } \\
\text { exclusión de } \\
\text { sociedades } \\
\text { financieras }\end{array}$ & $\begin{array}{l}\text { Exclusión de } \\
\text { sociedades } \\
\text { financieras y } \\
\text { entidades } \\
\text { aseguradoras }\end{array}$ & $\begin{array}{l}\text { Exclusión de } \\
\text { sociedades } \\
\text { financieras y } \\
\text { entidades } \\
\text { aseguradoras }\end{array}$ \\
\hline $\begin{array}{l}\text { Utilización de } \\
\text { estados consolidados }\end{array}$ & $\begin{array}{l}\text { Posibilidad de } \\
\text { utilizar los estados } \\
\text { consolidados }\end{array}$ & & \\
\hline
\end{tabular}

Fuente: Elaboración propia.

\section{BIBLIOGRAFÍA Y FUENTES}

\section{Bibliografia}

Agencia Tributaria. Subdirección General de Ordenación Legal y Asistencia Jurídica. Nota $\mathrm{n}^{\mathrm{o}} 1 / 15$ relativa a la limitación de gastos financieros prevista en el artículo 16 de la ley 27/2014 de 27 de noviembre.

Alonso ARCE, I., La limitación a la deducción de gastos financieros en el Impuesto sobre Sociedades. Forum Fiscal no 234, junio 2018.

CALDERón CARRERO, J. M., «STJCE 13.3.2.007, C-524/04, Asunto Test Claimants in the Thin Cap Group: las Condiciones de compatibilidad comunitaria de las cláusulas de subcapitalización (y de precios de transferencia)» en Crónica Tributaria $n^{\circ} 155,2015$.

CALvo Vérgez, J., «La nueva limitación a la deducibilidad de gastos financieros en el Impuesto sobre Sociedades: algunas consideraciones a la luz de la reforma fiscal» en Actum Fiscal $n^{\circ}$ 95. 2015. (EDA 2015/100069).

CASTRO ARANGO, K.M. «Límites a la capitalización encubierta en España: problemas comunitarios y convencionales de los nuevos artículos 20 y 14.1. h) del TRLIS» 
en Estudios financieros. Revista de contabilidad y tributación: Comentarios, casos prácticos núm 376, 2014.

Cencerrado Millán, E., «La subcapitalización» en Fiscalidad de los precios de transferencia (operaciones vinculadas).

ChevarríA, Z., «La naturaleza jurídica de la norma de subcapitalización y su aplicación práctica como norma doméstica antielusión en el Reino de España» en Revista del Departamento Académico de Ciencias Administrativas, año 3, número 5. 2008.

Comunicación de 10 de diciembre de 2007 de la Comisión al Consejo, al Parlamento Europeo y al Comité Económico y Social Europeo sobre aplicación de medidas contra las prácticas abusivas en el ámbito de la fiscalidad directa dentro de la UE y en relación con terceros países.

Consejo Europeo. Consejo de la Unión Europea. Base imponible consolidada común del Impuesto sobre Sociedades. https://www.consilium.europa.eu/es/policies/ccctb/ (Última consulta 9 de marzo de 2019).

EURopeAn Commission. The Anti Tax Avoidance Directive. https://ec.europa.eu/taxation_customs/business/company-tax/anti-tax-avoidance-package/anti-taxavoidance-directive_en (Última consulta 9 de marzo de 2019).

—. Anti Tax Avoidance Package. https:/ec.europa.eu/taxation_customs/business/ company-tax/anti-tax-avoidance-package_en (Última consulta 9 de marzo de 2019).

FALCÓN Y TELlA, R., «La subcapitalización, las ETVE y la planificación fiscal «de riesgo» /Res. TEAC 25 junio 2009)» en Revista Quincena Fiscal núm. 22/2009 parte Editorial. Cizur Menor: Editorial Aranzadi, S.A.U, 2009.

Fuster Tozer, R.; Durán Haeussler, C.; Villalón Pérez-Artacho, J.; ArtamenDi GutiÉrRez, A.L., «Capítulo IV. Acción 4: Limitación de la erosión de la base imponible por vía de deducciones de intereses y otros gastos financieros» en Plan de acción BEPS: Una reflexión obligada. Madrid: Fundación de Impuestos y Competitividad, 2017.

García Novoa, C., La deducibilidad de gastos financieros en el Impuesto de Sociedades. Madrid: Marcial Pons. 2016.

García EsPinar, E.; Viñas Rueda, L., Sobre la posible vulneración del derecho comunitario por parte de la norma española que limita la deducibilidad de los gastos financieros. (LA LEY 4672/2017).

GómEz SuÁREZ, M.A., La intervención de la fiscalidad en el desplazamiento interjurisdiccional de las estructuras financieras de los grupos multinacionales. A Coruña: Universidade Da Coruña, 2015.

Gorospe Oviedo, J. I. y Herrera Molina, P. M., «La interpretación favorable al contribuyente ante la oscuridad normativa» en Crónica Tributaria núm. 100, 2001.

LAgo Montero, J.M., «Planificación fiscal agresiva, BEPS y litigiosidad» en Ars Iuris Salmanticensis. Estudios. Vol. 3, Diciembre 2015.

LÓPEZ RIBAS, S., El principio de libre competencia y los gastos financieros. 2016 (LA LEY 788/2016).

LuCAS DuRÁn, M. Subcapitalización e imposición societaria en el País Vasco. 2014. MARTín SeSma, F., «Medidas del proyecto BEPS implantadas por la UE y en el reino de España: territorio de régimen común y territorios forales (I)» en Forum Fiscal $n^{\circ} 244$, julio 2018 . 
MEMENTo Fiscal. «Limitación de la deducibilidad de los gastos financieros». 2016.

Mendoza López, D.T.; Valdez Aguirre, F., El plan de acción OCDE/G20 en la construcción del pacto global por la justicia fiscal. Cizur Menor: Editorial Aranzadi, S.A.U., 2018.

Merino Jara, I., BEPS, Unión Europea y Hacienda Foral. Proyecto de Investigación «La residencia fiscal ante la diversidad de poderes tributarios desde la perspectiva del País Vasco». DER2015-63533-C4-1-P. MINECO/FEDER.

Palao Taboada, C., «La subcapitalización», en Serrano Antón, F. (Dir.), Fiscalidad internacional, 4a ed.. Madrid: CEF, 2010.

PAREJO GARCÍA, B., «La regla de la delimitación de deducibilidad de intereses» en Almudí CID, J.M. La armonización de las normas contra la elusión fiscal relativas a la fiscalidad directa en la Unión Europea. Cizur Menor: Editorial Aranzadi S.A.U., 2018 (BIB 2018\11536).

TABOADA, C., «La subcapitalización y los convenios de doble imposición» en Revista de Contabilidad y Tributación, núm. 137/138. 1995.

OCDE. «10 preguntas sobre BEPS» https://www.oecd.org/ctp/10-preguntas-sobrebeps.pdf (Última consula 21 de marzo de 2019).

— Directrices de la OCDE aplicables en materia de precios de transferencia a empresas multinacionales y administraciones tributarias. 2010.

OECD (2015), Limiting Base Erosion Involving Interest Deductions and Other Financial Payments, Action 4 - 2015 Final Report, OECD/G20 Base Erosion and Profit Shifting Project, OECD Publishing, Paris. http://dx.doi. org/10.1787/9789264241176-en (Última consulta 21 de marzo de 2019).

OCDE. Model Tax Convention on Income and on Capital (Condensed version as it to read on 21 november 2017). 2017.

—. «Nota explicativa. Informes Finales 2015» en Proyecto OCDE/G20 sobre la Erosión de la Base Imponible y el Traslado de Beneficios. 2015.

- «Progress report July 2017-June 2018» en OECD/G20 Inclusive Framework on BEPS. 2018.

—. «Resúmenes. Informes Finales 2015» en Proyecto OCDE/G20 sobre la Erosión de la Base Imponible y el Traslado de Beneficios. 2015.

OtAegi, I.; ARmesto, D. Material «Fiscalidad Internacional» del máster en Asesoría Fiscal. Cámara de Comercio, Bilbao.

PÉrez Delgado, A., «Modificaciones en la BI de la Directiva contra la elusión fiscal». Foro Aranzadi. Thomson Reuters Formación.

Ruiz Almendral, V., Subcapitalización y libertad de establecimiento: el caso "Test Claimants in the Thin Cap Group Litigation» como una oportunidad para rehabilitar el artículo 20 del TRLIS. 2008.

SuÁrez de Centi Martínez, L.; Viana Barral, V., «La limitación a la deducibilidad de gastos financieros en el Impuesto sobre Sociedades: Análisis normativo y comentario crítico» en Actualidad Jurídica (Uría \& Menéndez), núm. 33. 2012.

Vega BorRego, F. A., «La norma tributaria en materia de subcapitalización: incidencia de los convenios de doble imposición y del derecho comunitario» en Crónica Tributaria $n^{\circ}$ 104. 2002. 


\section{Legislación}

\section{- Territorio Común}

Real Decreto de 24 de julio de 1889 por el que se publica el Código Civil («BOE» núm. 206, de 25 de julio de 1889).

Ley 61/1978, de 27 de diciembre, del Impuesto sobre Sociedades («BOE» núm. 312, de 30 de diciembre de 1978).

Ley 18/1991, de 6 de junio, del Impuesto sobre la Renta de las Personas Físicas («BOE» núm. 136, de 7 de junio de 1991).

Ley 43/1995, de 27 de diciembre, del Impuesto sobre Sociedades («BOE» núm. 310, de 28 de diciembre de 1995).

Real Decreto 1514/2007, de 16 de noviembre, por el que se aprueba el Plan General de Contabilidad («BOE» núm. 278, de 20 de noviembre de 2007).

Real Decreto-ley 12/2012, de 30 de marzo, por el que se introducen diversas medidas tributarias y administrativas dirigidas a la reducción del déficit público («BOE» núm. 78, de 31 de marzo de 2012).

Ley 27/2014, de 27 de noviembre, del Impuesto sobre Sociedades («BOE» núm. 288, de 28 de noviembre de 2014).

\section{- Bizkaia}

Norma Foral 3/1996, de 26 de junio, del Impuesto sobre Sociedades («BOB» 11 de julio de 1996).

Ley 12/2002, de 23 de mayo, por la que se aprueba el Concierto Económico con la Comunidad Autónoma del País Vasco («BOE» núm. 124, de 24 de mayo de 2002).

Norma Foral 11/2013, de 5 de diciembre, del Impuesto sobre Sociedades («BOB» de 13 diciembre de 2013).

Norma Foral 2/2005, de 10 de marzo, General Tributaria del Territorio Histórico de Bizkaia («BOB» de 11 Marzo de 2005).

Norma Foral 2/2018, de 21 de marzo, por la que se caracterizan a efectos tributarios determinados fondos de inversión a largo plazo europeos y se introducen modificaciones en las Normas Forales del Impuesto sobre la Renta de las Personas Físicas, del Impuesto sobre Patrimonio, del Impuesto sobre Sociedades, del Impuesto sobre Transmisiones Patrimoniales y Actos Jurídicos Documentados, del Impuesto sobre Sucesiones y Donaciones y del Régimen fiscal de Cooperativas, así como en la Norma Foral General Tributaria del Territorio Histórico de Bizkaia («BOB» núm. 61, de 27 de marzo de 2018).

\section{- Unión Europea}

Directiva (UE) 2017/952 del Consejo, de 29 de mayo de 2017 por la que se modifica la Directiva (UE) 2016/1164 en lo que se refiere a las asimetrías híbridas con terceros países. «DOUE» L 144/1 de 7 de junio de 2017. 
Directiva (UE) 2016/1164 del Consejo, de 12 de julio por la que se establecen normas contra las prácticas de elusión fiscal que inciden directamente en el funcionamiento del mercado interior. «DOUE» L 193/1 de 19 de julio de 2016.

Directiva 2011/96/UE del Consejo de 30 de noviembre de 2011 relativa al régimen fiscal común aplicable a las sociedades matrices y filiales de Estados miembros diferentes. «DOUE» L 345/8 de 29 de diciembre de 2011.

Tratado de Funcionamiento de la Unión Europea. «DOUE» C 326/49.

\section{Jurisprudencia}

Sentencia del Tribunal de Justicia de la Unión Europea (Sala Quinta) de 12 de diciembre de 2002, as. C-324/00, Lanhorst Hohorst (ECLI:EU:C:2002:749).

Conclusiones del Abogado General Sr. L.A. Geelhoed presentadas el 29 de junio de 2006- Asunto C-524/04.

Sentencia del Tribunal de Justicia de la Unión Europea (Gran Sala) de 13 de marzo de 2007, as. C-524/04, Test Claimants in the Thin Cap Group Litigation (ECLI:EU:C:2007:161).

Sentencia del Tribunal de Justicia de la Unión Europea (Sala Cuarta) de 3 de octubre de 2013, as. C-282/2012 - Itelcar (ECLI:EU:C:2013:629).

Sentencia del Tribunal Supremo (Sala $3^{\text {a) }}$ de 1 de octubre $n^{\text {o }} 7460 / 2009$ (ECLI:ES:TS:2009:7460).

Sentencia del Tribunal Supremo (Sala $3^{\mathrm{a}}$ ) de 17 de marzo $\mathrm{n}^{\mathrm{o}} 1825 / 2011$ ( $^{\mathrm{o}}$ rec. 5871/2006).

\section{Doctrina administrativa}

Dirección General de Tributos. Consulta 2055-97, de 9 de octubre de 1997.

Dirección General de Tributos. Consulta 1315-98, de 20 de julio de 1998.

Dirección General de Tributos. Consulta 1210-01, de 20 de junio de 2001.

Dirección General de Tributos. Consulta 1615-01, de 4 de septiembre de 2001.

Boletín Oficial del Instituto de Contabilidad y Auditoría de Cuentas. Consulta $\mathrm{n}^{\mathrm{o}} 1$, $\mathrm{n}^{\mathrm{o}}$ de BOICAC 78/junio 2009.

Resolución de 16 de julio de 2012, de la Dirección General de Tributos, en relación con la limitación en la deducibilidad de gastos financieros en el Impuesto sobre Sociedades («BOE» núm. 170 de 17 de julio de 2012). 


\title{
LA LIMITACIÓN A LA DEDUCIBILIDAD DE LOS GASTOS FINANCIEROS EN EL IMPUESTO SOBRE SOCIEDADES: EVOLUCIÓN Y ANÁLISIS COMPARATIVO
}

\author{
The limitation on interest deductions in the Law of Spain \\ and the Basque Country: Evolution and Comparison
}

\author{
Irene Martinez Martinez \\ Universidad de Deusto \\ irenemartinez.imm@gmail.com
}

http://dx.doi.org/10.18543/ed-67(2)-2019pp355-394

\section{Copyright}

Estudios de Deusto es una revista de acceso abierto, lo que significa que es de libre acceso en su in tegridad. Se permite su lectura, la búsqueda, descarga, distribución y reutilización legal en cualquier tipo de soporte sólo para fines no comerciales, sin la previa autorización del editor o el autor, siempre que la obra original sea debidamente citada y cualquier cambio en el original esté claramente indicado

Estudios de Deusto is an Open Access journal which means that it is free for full access, reading, search, download, distribution, and lawful reuse in any medium only for non-commercial purposes, without prior permission from the Publisher or the author; provided the original work is properly cited and any changes to the original are clearly indicated. 